\title{
Optimal Operation of a Residential Microgrid: The Role of Demand Side Management
}

\author{
Gabriella Ferruzzi $^{1}$ - Giorgio Graditi ${ }^{2}$ - Federico Rossi ${ }^{3} \cdot$ Angela Russo $^{4}$
}

Received: 14 March 2015 / Revised: 16 April 2015 / Accepted: 21 April 2015 / Published online: 24 May 2015

(C) Springer Science+Business Media Singapore 2015

\begin{abstract}
In this paper demand side management (DSM), characterized by shifting techniques, is applied to a residential microgrid. It is supposed that the microgrid is managed by a prosumer, a decision maker who manages distributed energy sources, storage units, ICT elements, and loads involved in the grid. DSM is considered as an integral part of the optimal economic short-term management problem such that the allocation of shiftable loads is treated as a variable must be determined simultaneously with all the others variables (i.e. energy exchange with the main grid, internal production, charge/discharge of electrical storage units). This paper focuses on the formulation of an economic model including functional links between shiftable and shifted loads
\end{abstract}

It is assumed that, in each interval of the management period, all of the time-dependent quantities are constant and equal to the end value of the prior interval.

Giorgio Graditi

giorgio.graditi@enea.it

Gabriella Ferruzzi

gxf14@psu.edu

Federico Rossi

federico.rossi@unina.it

Angela Russo

angela.russo@polito.it

1 The Pennsylvania State University, 302 Walker Building, University Park, PA 16802, USA

2 ENEA Italian National Agency for New Technologies, Energy and Sustainable Economic Development, Naples, Italy

3 Universita' di Napoli Federico II, Naples, Italy

4 Politecnico di Torino, Torino, Italy properly linked. The objective function is the minimization of the operation energy costs. The model is implemented using IBM ILOG CPLEX an optimization programming language solver. The analysis shows how the variable allocation of shiftable loads is related to the other variables and how all the variables are linked (directly or indirectly) to the energy price and to the other parameters typical of shiftable energy devices. Moreover, the model allows to easily perform sensitivity analyses by varying the parameters considered. For instance, transitioning from the pre-shift to post-shift state, an improvement of the economic objective corresponds to an enhancement in the utility load profile. A sensitivity analysis is carried out by varying the maximum amount of power exchanged with the main grid. Results provide useful information to find a compromise between connecting interests. Numerical results are presented and discussed.

Keywords Residential microgrid · Demand side management (DSM) - Shifting modelling · Time of use (TOU) . Real time pricing (RTP) tariff

\section{List of Main Symbols}

$\begin{array}{ll}\Omega_{D_{S H}} & \text { Set of shiftable loads } \\ \Omega_{D_{F}} & \text { Set of fixed loads } \\ \Omega_{D_{e}} & \text { Set of total electrical loads }\left(\Omega_{D_{F}} \text { and }\right. \\ & \left.\Omega_{D_{S H}}\right) \\ \Omega_{D_{G}} & \text { Set of thermoelectric power plants } \\ \Omega_{D_{R E S}} & \text { Set of total renewable energy sources } \\ P_{D_{e_{t, j}}}^{\prime} & \text { Pre-shift load } \\ P_{D_{e_{t, j}}} & \text { Post-shift load } \\ D_{S H_{t, j}} & \text { Shiftable power of the } j \text { th cluster at } t \text { th hour }\end{array}$ 


$\begin{array}{ll}d_{S H_{t, j}} & \begin{array}{l}\text { Shiftable power of the } j \text { th single device at } \\ t \text { th hour }\end{array} \\ P_{D_{S H_{t, j}}} & \begin{array}{l}\text { Shifted power of the } j \text { th shiftable load at } \\ t \text { th hour }\end{array} \\ P_{D F_{t, j}} & \begin{array}{l}\text { Power of the } j \text { th fixed load at } t \text { th hour } \\ \text { Power of the } j \text { th thermolectric unit at the } \\ P_{G_{t, j}}\end{array} \\ P_{R E S_{t, j}}^{e} & \begin{array}{l}\text { Power of the } j \text { th not programmable renew- } \\ \text { able unit at the } t \text { th hour }\end{array} \\ P_{S E_{t, j}} & \text { Power of the } j \text { th storage unit at the } t \text { th hour } \\ W_{S E_{t, j}} & \text { Level of the } j \text { th storage unit at the } t \text { th hour } \\ C_{G_{t, j}} & \text { Production cost of the } j \text { th thermoelectric } \\ & \text { unit at } t \text { th hour } \\ P_{g r i d_{t}} & \text { Power interchanged with the MV network } \\ & \text { at the } t \text { th hour } \\ \rho_{t} & \text { Energy price, using a TOU or RTP tariff } \\ \rho_{t}^{s} & \text { Energy market price } \\ k_{T} & \text { Unit cost of trasmission } \\ S_{j} & \text { Cycle duration of the single device } \\ s_{t} & \text { Hourly interval of } S_{j} \\ T_{j} & \text { Time windows of the single device } \\ T_{j}^{s t} & \text { Time at which the } j \text { th shiftable load starts } \\ u_{t, j} & \text { Binary variable }\end{array}$

\section{Introduction}

Demand side management (DSM) can be defined as modifications in the demand side energy consumption pattern to foster better efficiency and operations in electrical energy systems $[1,2]$. It is usually implemented in order to obtain a desired electrical load profile [3] for a predefined control period, which is typically one day.

The reduction of the peak load is one of the objectives of DSM to avoid new generation capacity helping utilities to reduce their operational cost and environment to be free from excess carbon foot prints [4]. DSM techniques exploit characteristics of some controllable loads. Generally, controllable loads can be classified into curtailable and shiftable loads $[5,6]$. The first category refers to loads that can be reduced or switched off during specific time periods; the second one refers to loads that can be postponed to a later time. The shifting techniques are predominant in the residential and commercial sectors whereas the shedding techniques are prelevant in the industrial sector [7].

Residential load management programs usually aim at one or both of following objectives: reducing consumption and shifting consumption [8]. This work considers only shifting techniques applied to the residential sector.

Traditional DSM measures, promoted by the distributor system operator (DSO), are mainly used to smooth the utility load profile. Shaving the peaks and fill load profile provide a several benefits for the DSO and the transmis- sion system operator (TSO) [4,9-11]. For example, one advantage is the reduction in the peak load that increases the reserve capacity and, consequently, the power system security margin. Moreover, the peak reduction can be used to defer future network reinforcement due to load growth $[12,13]$. For this reason, since the early 1980 s, various programs have been implemented to encourage the participation of users with varying degrees of success [14]. In the typical incentive-based programs (IBPs), participating users receive payments for their participation, usually as a bill credit or discount rate. Conversely, price-based programs (PBPs) change the tariff correspondingly to peak or off-peak periods.

High energy tariffs are used for peak periods as well as low energy tariffs are considered for off-peak periods [14]. These latter rates include among others the time of use (TOU) and the real time price (RTP) ratings. The unit electricity price varies with the TOU rates in the different time slots. The simplest TOU rate has two time slots $[10,15,16]$ : the peak and the off-peak times. The rate design attempts to reflect the average cost of electricity during different time intervals.

With the RTP rate, the electricity price varies hourly for the user to consider the real cost of electricity in the wholesale market. RTP customers are informed one day ahead about the hourly prices $[14,17]$. Therefore, a win-win situation could be created with PBPs, where the users can pursue their own interests, by passively respecting indications of the DSO.

Despite the presence of many DSM programs promoted by the DSO over the years, DSM has been investigated only in recent years, and in a few cases, for operation in conjunction with a medium-voltage (MV) distribution network [18-20]. Advances in smart metering technologies and increasing interest in infrastructure with two-way digital communication capability through computing networks make microgrids and smart grids the best applications for DSM [18,21,22]. In our work the DSM is applied to a residential microgrid managed by a prosumer.

The prosumer in this context is often a decision maker responsible for distributed energy sources, storage units, ICT elements, and loads involved in the microgrid [11, 19,23-28]. The different power plants and loads involved to the microgrid appear to the DSO as a single entity which produces or absorbs energy. Thus, independently of the DSO, the microgrid can achieve an economic optimal short-term management by considering DSM $[29,30]$. Therefore, optimal values of the variables (e.g., the energy exchanged with the main grid, the internal production and the charge/discharge of electrical storage units) must be determined simultaneously. This result can be obtained by communication among the devices and the control/dispatch center. 
This paper focuses on the formulation of an economic optimization model including functional links between shiftable and shifted loads. By solving the optimization problem, the link among the discrete variable allocation of shiftable loads and the other continuous variables involved is highlighted. The direct or indirect relationship among all the variables and the energy price as well as the relationship among all the variables and the other parameters typical of the shiftable devices is shown.

Moreover, the model simplifies sensitivity studies carried out to investigate changes in the many parameters involved such as: composition of the generation system of the microgrid, load pre-shift profile, percentage of total shiftable load, characteristics of the devices, structure of the tariffs, price profile and the regulatory framework.

Sensitivity analysis provides interesting suggestions. In literature [20,22,31], there are situations where contradicting results have been found. These are examples where both the prosumer and DSO do not benefit from effective demand side management.

It can occur that, moving from the pre-shift to post-shift state, an improvement in the economic objective for the prosumer does not correspond to an enhancement of the utility load profile [17].

The DSO, desiring a flat load profile, imposes limitations on the maximum amount of power exchanged [17], with a resultant economic loss for the prosumer. Results of the analysis allow planners to decide whether it is appropriate to find a compromise solution between the different conflicting interests. Differences are evident among other models set forth in the current literature.

In fact many of the existing models, i.e. in [19,23,31], deal with domestic microgrid production which consists only of non-programmable renewable sources.

Different objective functions have been adopted. For example, in [19] only the cost of energy purchased is considered. In [31] revenues from the sale of PV energy are also considered, without express any exclusivity constraint with the energy purchased. In [20] the authors want to minimize the distance between a load consumption curve and an objective curve, which is inversely proportional to market prices, so that the loads can shift from the time intervals characterized by high price to the time intervals with lowest price.

The work is structured in six sections. In the "The Load Shifting Model" Section the analysis of shiftable loads in the residential sector and the analytical relations between shiftable and shifted loads are shown. The aim is to formulate the general model of short-term management discussed in "The DSM Model" Section. A detailed analysis of the model solutions is reported in "Solution analysis" Section. In "Case Study" Section the model is applied to a specific case study and the results are presented and discussed in "Conclusions" Section.

\section{The Load Shifting Model}

The following users can be subjected to load management actions:

- users at fixed cycle, characterized by a functioning of duration divisible into well-identified sub-cycles adjustable according to the procedures properly prepared in the design phase (i.e. washing machines);

- some thermally sensitive users, characterized by a cyclic functioning and closely dependent on external conditions (i.e. air-conditioners).

Service devices (i.e. televisions and computers) can not be subject to load management actions, since their functionsstart time, duration and level of power absorption-are determined by the needs of the end consumers, which are strictly subjective and difficult to predict.

In this paper, washing machines, dishwashers, dryers, irons, air conditioners and coffee makers are considered shiftable loads.

The $j$ th device is described by a set of simple parameters:

- the cycle duration (h), $S_{j}$;

- the power used during the process $(\mathrm{kW}), d_{S H_{t}, j}$;

- the time in which the process can be postponed (h), said time window, $T_{j}$;

- the starting time (h), $T_{j}^{s t}$.

The cycle duration depends on the technological maturity of the individual devices and, for some devices such as washing machines and dishwashers, cycle duration even depends on the wash cycle chosen by the user.

Furthermore, the amount of power required by the device depends on the technological maturity of the device as well. For instance, the energy consumption of washing machine can be influenced by the type of cleaning program required. The power required by the device can be inconsistent during the process. The period in which the cycle can be postponed is a function of the availability and behavior of the consumer, as well as the starting time of the process (a coffee maker does not have the same flexibility as a dishwasher).

By using this information derived from statistical surveys [3], it was possible to identify the shiftable profile of each device. To determine the hourly profile of shiftable total loads, it is appropriate that the devices be clustered. Each cluster includes devices with the same $S_{j}$ and $T_{j}$ or, as we did, the devices of the same type. Consequently, a cluster is composed of a set of irons, rather than, a set of coffee makers.

The total power of each cluster is computed by summing the relative contribution of each device belonging to the cluster. Maintaining the same index $j$ also for the cluster composed by devices of the same $j$ th type, the hourly power of each cluster, $D_{S H_{t, j}}$, is: 
$D_{S H_{t, j}}=N_{j} \cdot d_{S H_{t, j}}$,

where $N_{j}$ is the number of all $j$ th devices present in the microgrid and available to be shifted and $d_{S H_{t, j}}$ is the shiftable power by a single device $\mathrm{j}$, assumed to be the same for all the devices. In closing, the profile of shiftable loads is added to the profile of fixed loads. Note that, contrary to what is stated in $[18,19]$, this paper adds the consumption of different devices of the same type and does not add the consumption of the apartments. In fact, it appears incorrect to assume that each apartment has the same number and type of devices. Now, it is necessary to define a suitable shifting model to be implemented into the general management model. The relationship between the loads before and after shifting can be represented by introducing binary variables $u_{t, j}$.

The condition $u_{t, j}=1$ identifies the initial interval $\mathrm{t}$ where the $j t h$ shiftable load starts to be supplied for the next $S_{j}$ hours. Considering that the profile of the $j$ th shiftable load starts only once, only a binary variable can be equal to one. Moreover, only the first $\left(T_{j}-S_{j}+1\right)$ binary variables can be defined because each $u_{t, j}$ variable is associated with the next $\left(S_{j}-1\right)$ variables $P_{D_{S H_{t, j}}}$.

It must happen that:

$$
\sum_{t=1}^{T_{j}-\left(S_{j}-1\right)} u_{t, j}=1 \quad\left(j \in \Omega_{D_{S H}}\right)
$$

Then, let us consider that only the variables associated

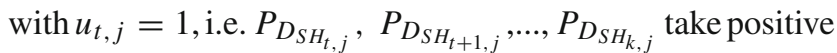
values. Specifically, each $P_{D_{S H_{t, j}}}$, with $k=t-s+1$, takes the value $D_{S H_{t-k+1, j}}$.

This way, the links between shiftable and shifted loads are:

$$
\begin{aligned}
P_{D_{S H_{t, j}}}= & \sum_{s=1}^{t} D_{S H_{(t-k+1, j)}} \cdot u_{k, j} \\
& \left(j \in \Omega_{D_{S H}} ; t=1, \ldots, T_{j}-S_{j}+1\right)
\end{aligned}
$$

The best moment to meet shiftable loads (i.e. the optimal determination of the variables), $u_{t, j}$, depends on the objective function to be optimized. In addition, the load can not be shifted $\left(u_{1, j}=1\right)$.

\section{The DSM Model}

If it is assumed that the tariffs are used to buy and sell energy, the optimal determination of controllable load profiles can be achieved by considering the internal distribution network as a busbar. In this system, all generating units and loads are directly connected. ${ }^{1}$

For the moment, storage units are not considered. The challenge is to minimize the following objective function that expresses the difference between costs and revenues subjected to a set of equality and inequality constraints:

$$
\sum_{t=1}^{24}\left[\sum_{j \in \Omega_{G}} C_{G_{j}}\left(P_{G_{j}}\right)+\rho_{t} P_{\text {grid }_{t}}\right]
$$

In (1), the revenues are obtained by the sale of energy to the MV network and the costs are linked by the internal production and purchase of energy from the MV network.

It is possible to assume that the variable costs associated with the shift are negligible for the residential sector. ${ }^{2}$

In (1), the price of energy at the $t t h$ hour, $\rho_{t}$, is supposed to be equal in the buying and selling phases. ${ }^{3}$ Here, the buying and selling is to be completed in a context focused on facilitating the development of microgrids and an awareness of the benefits provide (i.e. a friendly context).

The energy pricing takes the market price, $\rho_{t}^{s}$, and the unit cost of transmission $k_{T}$ into account, ${ }^{4}$ that is:

$\rho_{t}=\rho_{t}^{s}+k_{T}$

Equality constraints are the energy balance constraints:

$$
\begin{aligned}
& \sum_{j \in \Omega_{G}} P_{G_{t, j}}+P_{g r i d_{t}}+\sum_{j \in \Omega_{R E S}} P_{R E S_{t, j}}^{e}=\sum_{j \in \Omega_{D_{F}}} P_{D F_{t, j}} \\
& +\sum_{j \in \Omega_{S H}} P_{D_{S H t, j}}(t=1, \ldots, 24)
\end{aligned}
$$

and the constraints that express the links between shiftable and shifted load, are the following:

$$
\begin{aligned}
& P_{D_{S H t, j}}=\sum_{s=1}^{t} D_{S H_{(t-k+1), j}} \cdot u_{k, j} \\
& \quad\left(j \in \Omega_{D_{S H}} ; t=1, \ldots, T_{j}-S_{j}-1\right)
\end{aligned}
$$

\footnotetext{
${ }^{1}$ For simplicity, the loads of the microgrid are only electrical loads. If thermal loads exist, the thermal energy is produced by the boilers.

2 Investment costs can be significant. They include costs for the smart meter, software and maintenance of the control center, the energy management system and the data exchange unit.

${ }^{3}$ If the selling price is different from the purchase price, it is necessary to introduce an exclusivity constraint [32], using, for instance, a new binary variable that takes the value 1 if the microgrid sells power to the main grid and takes the value 0 if the microgrid buys power from the main grid.

${ }^{4}$ In a hostile context, the microgrid buys and sells energy at different prices; it buys energy at a high price (obtained by summing the wholesale market, transmission and distribution prices) and sells energy at the wholesale market price [5].
} 
Fig. 1 Hourly electrical internal loads

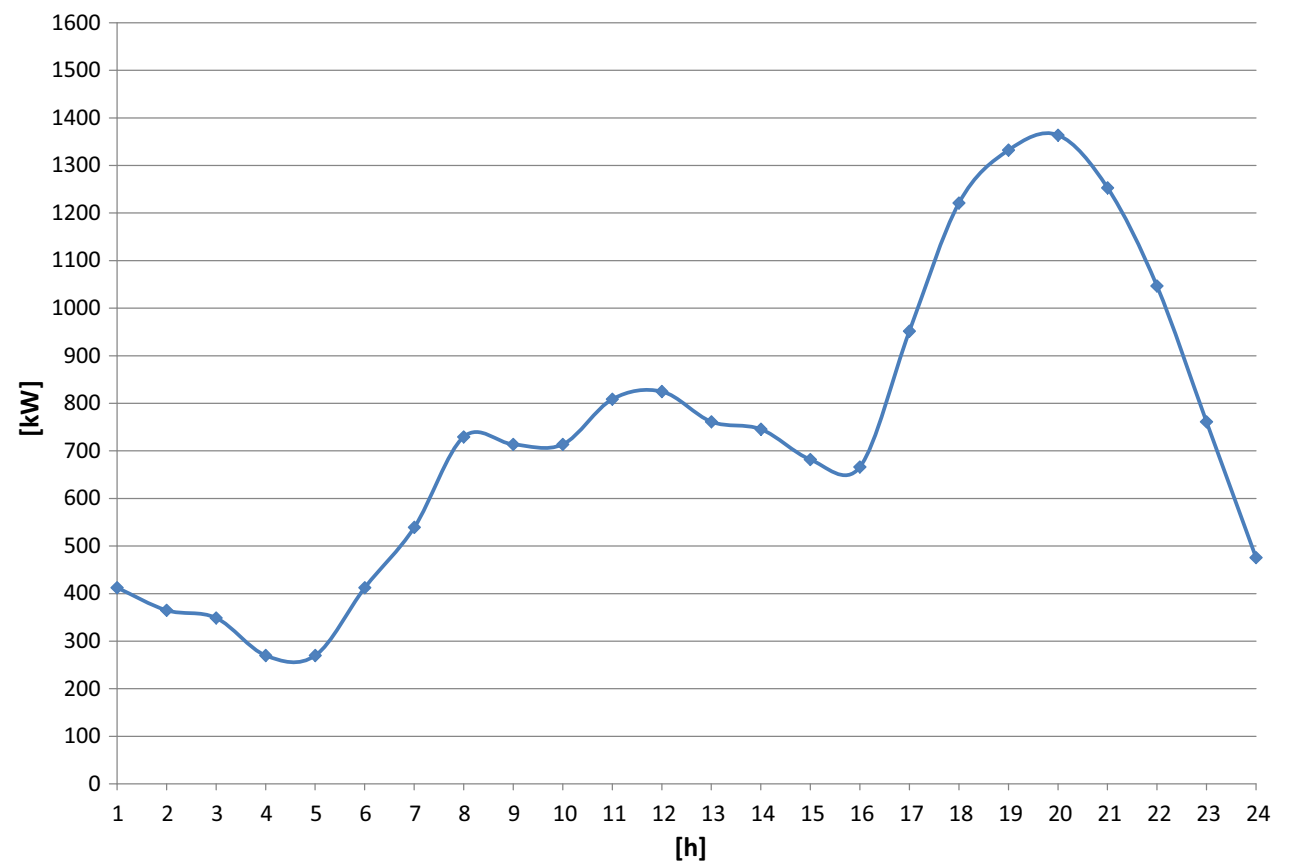

$\sum_{t=1}^{T_{j}-\left(S_{j}-1\right)} u_{t_{j}}=1 \quad\left(j \in \Omega_{D_{S H}}\right)$

with $k=t-s+1$.

In (2), $P^{e} R E S_{t, j}$ is assumed to be deterministic and calculable by the use of adequate forecasting techniques.

Inequality constraints express the limits on internal production and maximum amount of exchangeable power, bought or sold, in the main grid:

$$
\begin{aligned}
& P_{G_{t, j}}^{m} \leq P_{G_{t, j}} \leq P_{G_{t, j}}^{M} \quad\left(j \in \Omega_{g} ; t=1, \ldots, 24\right) \\
& -P_{\text {grid }}^{M} \leq P_{\text {grid }_{t}} \leq P_{\text {grid }}^{M} \quad(t=1, \ldots, 24)
\end{aligned}
$$

When there are storage units, the objective function is the same because the operation costs of storage can be neglected. On the other hand the structure of constraints changes and the balance constraints become:

$$
\begin{aligned}
& \sum_{j \in \Omega_{G}} P_{G_{t, j}}+P_{g r i d_{t}}+\sum_{j \in \Omega_{R E S}} P_{R E S_{t, j}}^{e}=\sum_{j \in \Omega_{D_{F}}} P_{D_{F_{t, j}}} \\
& +\sum_{j \in \Omega_{S H}} P_{S H_{t, j}}+\sum_{j \in \Omega_{S E}} P_{S E_{t, j}}
\end{aligned}
$$

Additional equality constraints can be derived from modeling the storage units. In fact, it is necessary to express the:

- variation of the storage levels;

- restoration of the initial levels.
Additional inequality constraints are:

$0 \leq W_{S E_{t, j}} \leq W_{S E_{j}}{ }^{M} \quad\left(j \in \Omega_{S E} ; t=1, . ., 24\right)$

$-P_{S E_{j}}{ }^{M} \leq P_{S E_{t, j}} \leq P_{S E_{j}}{ }^{M} \quad\left(j \in \Omega_{S E} ; t=1, \ldots, 24\right)$

Mathematically, the problem described is a mixed-integer programming problem.

\section{Solution Analysis}

The analysis of the solution shows that, under tariff regime RTP, each load is shifted, if own $T_{j}$ allows in the period, characterized by a number of hours equal to $S_{j}$, in which the following sum is minimized:

$$
\sum_{t=1}^{S_{j}} \rho_{t} \cdot D_{S H_{(t, j)}}
$$

This means that the load, if it is possible, will shift in the time intervals that minimize the shifting cost or, in different way, in the time intervals more convenient from economical point of view. That occurs in the RTP regime. On the other hand, in the TOU regime, each load is shifted if own $T_{j}$ allows in the intervals of the time $S_{j}$, in which the price is the lowest.

If $P_{\text {rrid }_{t}}$ results are internal to the definition range (10), the power generated is always the same before and after the shift, since the shift is only influenced by the prices. In fact, each 
Fig. 2 Power production curve of the PV plant

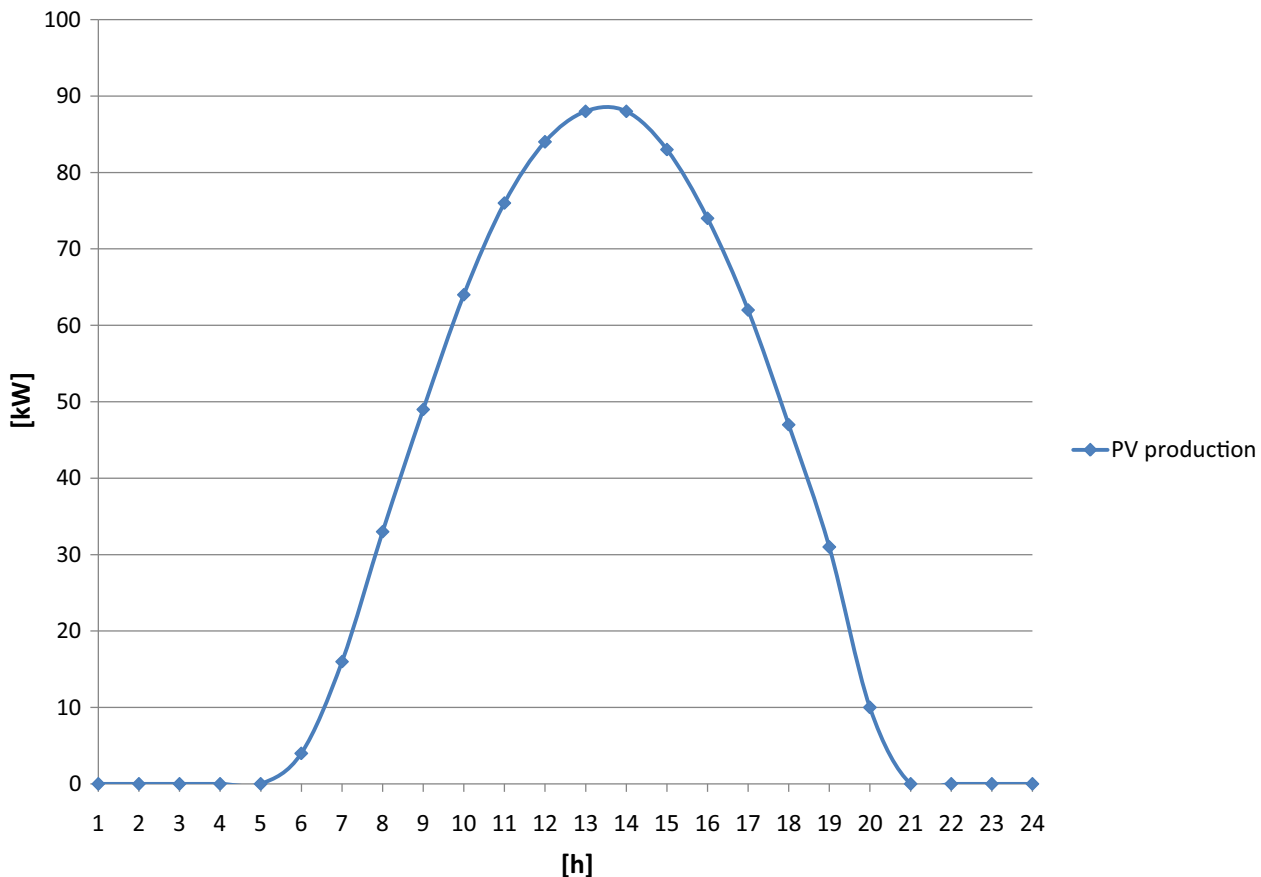

Table 1 Technical caracteristics of the shiftable devices

\begin{tabular}{|c|c|c|c|c|c|c|c|c|c|c|c|}
\hline \multirow[t]{2}{*}{ Device } & \multirow[t]{2}{*}{ Type } & \multirow[t]{2}{*}{$S_{j}[\mathrm{~h}]$} & \multicolumn{3}{|c|}{$d_{S H_{s, j}}[\mathrm{~kW}]$} & \multirow[t]{2}{*}{$N_{j}$} & \multicolumn{3}{|c|}{$D_{S H_{s, j}}[\mathrm{~kW}]$} & \multirow[t]{2}{*}{$T_{j}[\mathrm{~h}]$} & \multirow[t]{2}{*}{$T_{j}^{s t}[\mathrm{~h}]$} \\
\hline & & & $s_{1}$ & $s_{2}$ & $s_{3}$ & & $s_{1}$ & $s_{2}$ & $s_{3}$ & & \\
\hline 1 & Washing machine & 2 & 0.5 & 0.4 & & 99 & 49.5 & 39.6 & & 24 & 19 \\
\hline 2 & Washing and dryer & 3 & 0.5 & 0.4 & 1.2 & 189 & 94.5 & 75.6 & 283.6 & 24 & 19 \\
\hline 3 & Dishwasher & 2 & 0.7 & 0.7 & & 288 & 201.6 & 201.6 & & 24 & 22 \\
\hline 4 & Air conditioner & 3 & 0.2 & 0.2 & 0.2 & 288 & 57.6 & 57.6 & 57.6 & 3 & 10 \\
\hline 5 & Iron & 1 & 1.0 & & & 340 & 340 & & & 3 & 19 \\
\hline 6 & Coffee maker & 1 & 0.8 & & & 56 & 44.8 & & & 4 & 7 \\
\hline
\end{tabular}

Table 2 Technical and economic characteristics of the thermoelectric power plants

\begin{tabular}{llcccc}
\hline Power plants $(\mathrm{kW})$ & $P_{G_{j}}^{m}[\mathrm{~kW}]$ & $P_{G_{j}}^{M}[\mathrm{~kW}]$ & $\gamma_{G_{j}}[m$ euro $/ \mathrm{h}]$ & $\beta_{G_{j}}[m$ euro $/ \mathrm{kWh}]$ & $\alpha_{G_{j}}\left[m\right.$ euro $\left./ \mathrm{kWh}{ }^{2}\right]$ \\
\hline 400 & 80 & 400 & 1054 & 21.63 & 0.0005 \\
180 & 36 & 180 & 892 & 34.40 & 0.0021 \\
60 & 10 & 60 & 800 & 45.81 & 0.2222 \\
60 & 10 & 60 & 461 & 51.60 & 0.1000 \\
\hline
\end{tabular}

internal generator produces until the marginal cost is equal to the tariff price. All changes linked to the shift are absorbed by changes in $P_{\text {grid }}$. Therefore, the difference between the total energy absorbed and produced remains the same. The effectiveness of the shift, represented by the ability to improve the objective function, increases with the following parameters: value of the economic peak to valley, percentage of load shifted from the hours of high price to hours of low price, flexibility to use devices and amplitude of the time windows.

With a TOU tariff, the improvement of the objective does not depend on the level of flexibility. Therefore, in a scenario characterized by low flexibility, it is possible to obtain an economic benefit close to the case of high flexibility. The stated shifting criterion, as well as in the case of the classic DSM [19], may involve shaving of the original demand peaks, even 
Fig. 3 Marginal costs of the thermoelectric power plants

Fig. 4 RTP1 rate

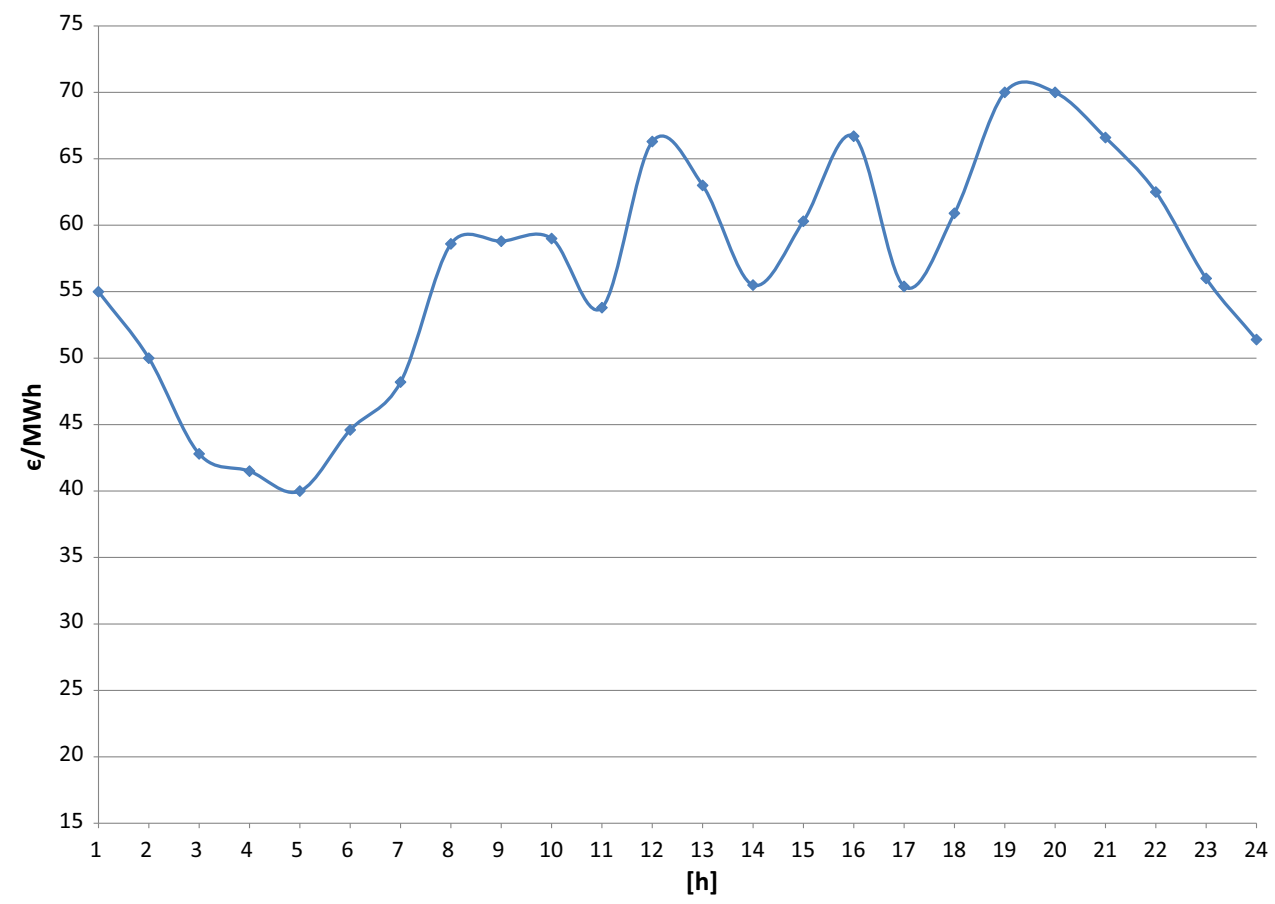

though alternative peaks higher/lower than to those removed might occur.

For a long time, there was a strong correlation between market prices and the electricity load where both profiles had a valley during the night and a peak during the day. However, this correlation was lost due to the rapid growth of non-programmable renewable energy, especially distributed solar energy. The growing supply of PV, with the maximum production in the summer and in the hours of highest solar irradiance, meant that the sustained loads at certain time intervals correspond to lowest prices.
The correlation loss occurred because the offers submitted to the energy market by non-programmable renewable sources, which have almost zero marginal costs, led to the exclusion from the market of the most expensive traditional power plants, thereby contributing to a reduction of the price. $^{5}$

\footnotetext{
$\overline{5}$ In the day-ahead auctions, the energy is valorised at market clearing price, that is the price in correspondence of equality between total quantity demanded and total quantity offered. Each seller or buyer, whose offer has been accepted, receives or pays the price determined at the equilibrium point.
} 
Table 3 Load profile structure

\begin{tabular}{|c|c|c|c|c|c|c|c|c|}
\hline Hour $[\mathrm{h}]$ & $\begin{array}{l}\sum_{j \in \Omega_{D_{e}}} P_{D_{e_{t, j}}}^{\prime} \\
{[\mathrm{kW}]}\end{array}$ & $\sum_{j \in \Omega_{D_{F}}} P_{D_{F_{t, j}}}$ & $D_{S H_{t, 1}}[\mathrm{~kW}]$ & $D_{S H_{t, 2}}[\mathrm{~kW}]$ & $D_{S H_{t, 3}}[\mathrm{~kW}]$ & $D_{S H_{t, 4}}[\mathrm{~kW}]$ & $D_{S H_{t, 5}}[\mathrm{~kW}]$ & $\overline{D_{S H_{t, 6}}[\mathrm{~kW}]}$ \\
\hline 1 & 412.3 & 412.3 & & & & & & \\
\hline 2 & 364.7 & 346.7 & & & & & & \\
\hline 3 & 348.8 & 348.8 & & & & & & \\
\hline 4 & 269.6 & 269.6 & & & & & & \\
\hline 5 & 269.6 & 269.6 & & & & & & \\
\hline 6 & 412.3 & 412.3 & & & & & & \\
\hline 7 & 539.0 & 494.4 & & & & & & 44.8 \\
\hline 8 & 729.4 & 729.4 & & & & & & \\
\hline 9 & 713.5 & 713.5 & & & & & & \\
\hline 10 & 713.5 & 655.9 & & & & 57.6 & & \\
\hline 11 & 808.7 & 751.1 & & & & 57.6 & & \\
\hline 12 & 824.5 & 766.9 & & & & 57.6 & & \\
\hline 13 & 761.1 & 761.1 & & & & & & \\
\hline 14 & 745.2 & 745.2 & & & & & & \\
\hline 15 & 681.8 & 681.8 & & & & & & \\
\hline 16 & 666.0 & 666.0 & & & & & & \\
\hline 17 & 951.4 & 951.4 & & & & & & \\
\hline 18 & 1220.9 & 1220.9 & & & & & & \\
\hline 19 & 1331.9 & 847.9 & 49.5 & 94.5 & & & 340.0 & \\
\hline 20 & 1363.6 & 1248.4 & 39.6 & 75.6 & & & & \\
\hline 21 & 1252.6 & 969.1 & & 283.5 & & & & \\
\hline 22 & 1046.5 & 844.9 & & & 201.6 & & & \\
\hline 23 & 761.1 & 559.5 & & & 201.6 & & & \\
\hline 24 & 475.5 & 475.5 & & & & & & \\
\hline
\end{tabular}

Therefore, it is not true that an effective DSM provides benefits to the prosumer and, at the same time, to the utilities. In fact, with the DSM, the prosumer improves (or, at least, does not worsen) the condition in terms of economic performance, but the DSO can worsen all the indexes of flattening related to the utility load diagram [33]: the peak value, the peak to valley and the standard deviation can increase; the load factor can decrease; the peak variation can assume a positive value.

When this happens, the DSO imposes more restrictive limits on the power exchanged with the main grid in the critical intervals when the prices are the lowest ones. The imposition of these limits does not automatically imply a different allocation of loads shifted, as it would be for a single user. A different load allocation only happens if it is less convenient to vary the domestic production. ${ }^{6}$ If, as it occurs more frequently, the critical intervals are intervals of consumption,

\footnotetext{
${ }^{6}$ The first order conditions of the optimization problem, taking the $P_{\text {grid }}$ on the bound, does not provide further equality between prices and marginal costs.
}

the restriction on importing $P_{\text {grid }}$ leads to an increase in domestic production with a waiver to buy. However, if the critical intervals are intervals of production, the limit on the export of $P_{\text {grid }}$ leads to a decrease in the internal production with a waiver to sell. The imposition of limits is equivalent to applying an ad hoc tariff that restores the peak in the day time and the valley in night time. It is possible to correct the prices in the critical hours with an RTP or TOU rate arranged in three time slots, with the night slots characterized by lowest prices, or in two time slots, with a less extensive nocturnal slots. Independently of the solution chosen, the prosumer is subject to an economic loss, which can be more or less important. Therefore, depending on the circumstances, the regulator, "super parties", should intercede by establishing when and how a compromise must be reached. It is to be underlined that, from a qualitative point of view, the grid management does not change if storage units exist in the system. In fact, the storage operates as the shift, discharging in the high-price intervals (from which loads are removed) and charging in the low-price intervals (in which the loads are relocated). Then, the effects of DSM and storage are added. 
Table 4 Pre-shift state with RTP1 rate

\begin{tabular}{|c|c|c|c|c|c|c|c|c|}
\hline Hour & $\rho_{t}$ & $P_{G_{t, 1}}$ & $P_{G_{t, 2}}$ & $P_{G_{t, 3}}$ & $P_{G_{t, 4}}$ & $\sum_{j \in \Omega_{G}} P_{G_{t, j}}$ & $P_{\text {grid }_{t}}$ & $\sum_{j \in \Omega_{D_{e}}} P_{D_{e_{t, j}}}^{\prime}$ \\
\hline 1 & 55.0 & 400.0 & 180.0 & 20.7 & 17.0 & 617.7 & -205.4 & 412.3 \\
\hline 2 & 50.0 & 400.0 & 180.0 & 10.0 & 10.0 & 600.0 & -235.3 & 364.7 \\
\hline 3 & 42.8 & 400.0 & 180.0 & 10.0 & 10.0 & 600.0 & -251.2 & 348.8 \\
\hline 4 & 41.5 & 400.0 & 180.0 & 10.0 & 10.0 & 600.0 & -330.4 & 269.6 \\
\hline 5 & 40.0 & 400.0 & 180.0 & 10.0 & 10.0 & 600.0 & -330.4 & 269.6 \\
\hline 6 & 44.6 & 400.0 & 180.0 & 10.0 & 10.0 & 600.0 & -187.7 & 412.3 \\
\hline 7 & 48.2 & 400.0 & 180.0 & 10.0 & 10.0 & 600.0 & -61.0 & 539.0 \\
\hline 8 & 58.6 & 400.0 & 180.0 & 28.8 & 35.0 & 643.8 & 85.6 & 729.4 \\
\hline 9 & 58.8 & 400.0 & 180.0 & 29.2 & 36.0 & 645.2 & 68.3 & 713.5 \\
\hline 10 & 59.0 & 400.0 & 180.0 & 29.7 & 37.0 & 646.7 & 66.8 & 713.5 \\
\hline 11 & 53.8 & 400.0 & 180.0 & 18.0 & 11.0 & 609.0 & 199.7 & 808.7 \\
\hline 12 & 66.3 & 400.0 & 180.0 & 46.1 & 60.0 & 686.1 & 138.4 & 824.5 \\
\hline 13 & 63.0 & 400.0 & 180.0 & 38.7 & 57.0 & 675.7 & 85.4 & 761.1 \\
\hline 14 & 55.5 & 400.0 & 180.0 & 21.8 & 19.5 & 621.3 & 123.9 & 745.2 \\
\hline 15 & 60.3 & 400.0 & 180.0 & 32.6 & 43.5 & 656.1 & 25.7 & 681.8 \\
\hline 16 & 66.7 & 400.0 & 180.0 & 47.0 & 60.0 & 687.0 & -21.0 & 666.0 \\
\hline 17 & 55.4 & 400.0 & 180.0 & 21.6 & 19.0 & 620.6 & 330.8 & 951.4 \\
\hline 18 & 60.9 & 400.0 & 180.0 & 34.0 & 46.5 & 660.5 & 560.4 & 1220.9 \\
\hline 19 & 70.0 & 400.0 & 180.0 & 54.4 & 60.0 & 694.4 & 637.5 & 1331.9 \\
\hline 20 & 70.0 & 400.0 & 180.0 & 54.4 & 60.0 & 694.4 & 669.2 & 1363.6 \\
\hline 21 & 66.6 & 400.0 & 180.0 & 46.8 & 60.0 & 686.8 & 565.8 & 1252.6 \\
\hline 22 & 62.5 & 400.0 & 180.0 & 37.6 & 54.5 & 672.1 & 374.4 & 1046.5 \\
\hline 23 & 56.0 & 400.0 & 180.0 & 22.9 & 22.0 & 624.9 & 136.2 & 761.1 \\
\hline 24 & 51.4 & 400.0 & 180.0 & 12.6 & 10.0 & 602.6 & -127.1 & 475.5 \\
\hline
\end{tabular}

\section{Case Study}

The proposed model is tested on a residential microgrid characterized by its internal electrical loads with reference to a summer day, as shown in Fig. 1.

The load is reduced by the PV power production (rated power is $100 \mathrm{~kW}_{p}$ ) reported in Fig. 2.

Washing machines, washing machines with dryers, dishwashers, electric air conditioners, irons and coffee makers are considered shiftable loads. Their characteristics are reported in Table 1.

The total number of such devices is 1260 .

In addition to the photovoltaic plant mentioned above, microgrid production system also includes four thermoelectric power plants, whose technical and economic characteristics are reported in Table 2. The coefficients $\alpha_{G_{j}}, \beta_{G_{j}}$ and $\gamma_{G_{j}}$ characterize the functions of the production costs of the plants. The functions are assumed to be quadratic. The marginal cost curves are shown in Fig. 3.

The maximum power exchanged with the main grid, $P_{\text {grid }}^{M}$, is assumed to be $1000 \mathrm{~kW}$. The control period start from the 19th hour of the current day, when the highest price occurs, to the 18th hour of the following day. Figure 4 shows that, in correspondence with RTP1 rate, the economic peak to valley index amounted to $30 €$. The model is implemented by using IBM ILOG CPEX optimization solver.

Table 3 reports some data about following loads: pre-shift load, ${ }^{7}$ fixed load and shiftable load. Tables 4 and 5 show the power produced and power exchanged with the main grid (that is the utility load) in the pre-shift and post-shift states, respectively.

Since $P_{\text {grid }}$ belongs to the definition range, the power generation is always the same before and after the shift. Next, has to be noted that not all loads can be placed according to (13) and that devices 4, 5 and 6 have time windows equal to 10,3 and 4 h, respectively. Figures 5 and 6 show the utility load and the microgrid load profiles inthe pre and post-shift states, respectively.

The shift involves the economic benefits as well as an improvement in the indices typical of a flattening utility

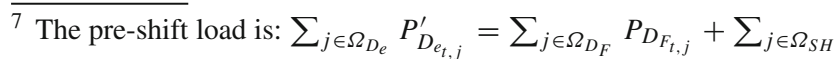
$D_{S H_{t, j}}$. The post-shift load is: $\sum_{j \in \Omega_{D_{e}}} P_{D_{e_{t, j}}}=\sum_{j \in \Omega_{D_{F}}} P_{D_{F_{t, j}}}+$ $\sum_{j \in \Omega_{S H}} P_{S H_{t, j}}$. In presence of storage units, the two above mentioned relations must to be completed adding the total power of storage units, $\sum_{j \in \Omega_{S E}} P_{S E_{t, j}}$. 


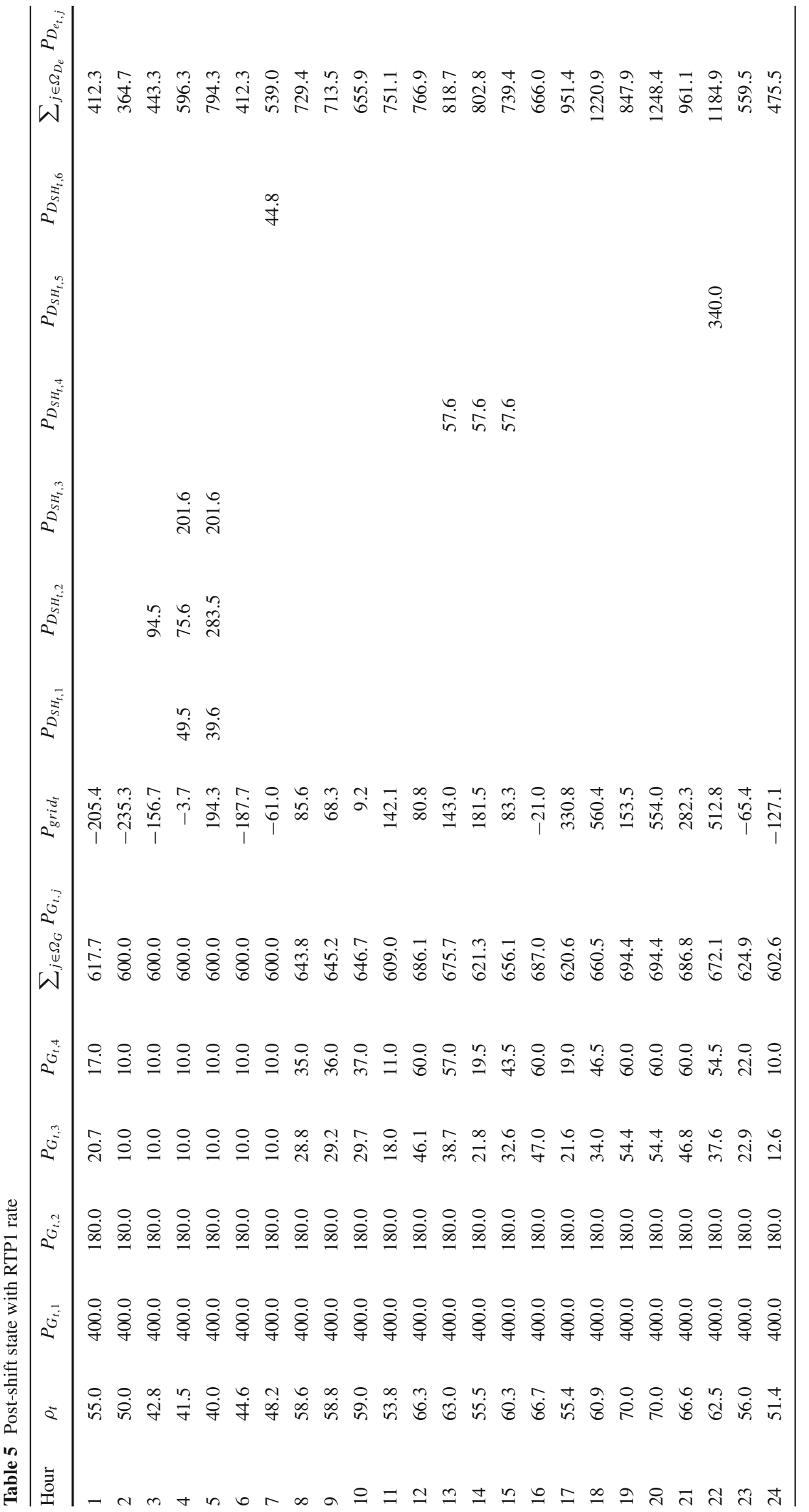


Fig. 5 Pre-shift state: utility and microgrid load with RTP1 rate

Fig. 6 Post-shift state: utility and load with RTP1 rate
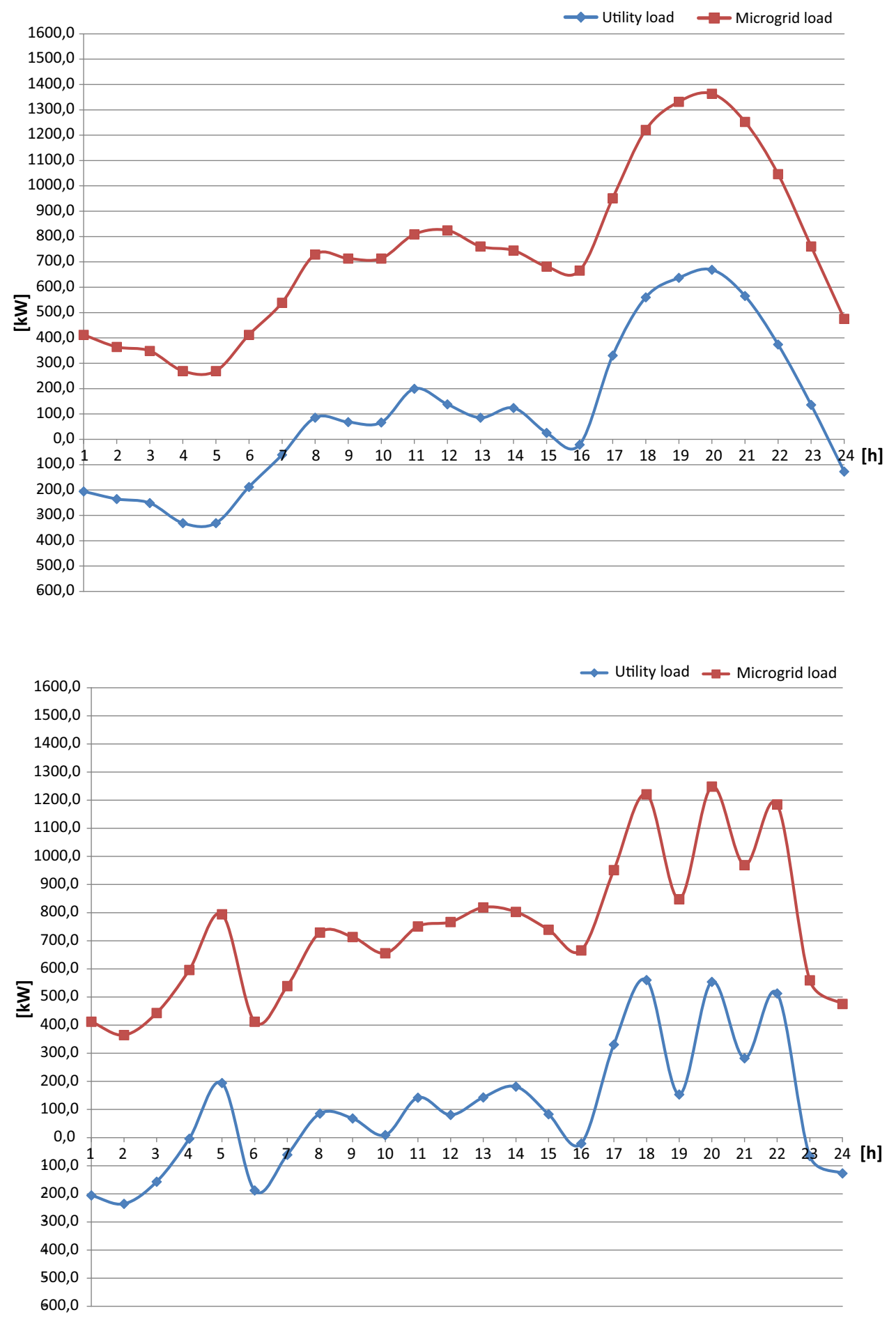

load profile, as evidenced in the summary tables (Tables 12 and 13). The situation is different if the RTP2 rate, that has an economic peak to valley equal to $34.5 €$, is adopted (Fig. 7).

Model results of the optimization problem for the RTP2 tariff are reported in Tables 6 and 7.
All shiftable loads move to the time characterized by the lowest energy prices, producing new peak loads, that are higher than those deleted with a consequent worsening of the indices of flattening (Tables 12 and 13). Figures 8 and 9 show the utility and microgrid load profiles in thepre and post-shift states, respectively. 
Fig. 7 RTP2 rate

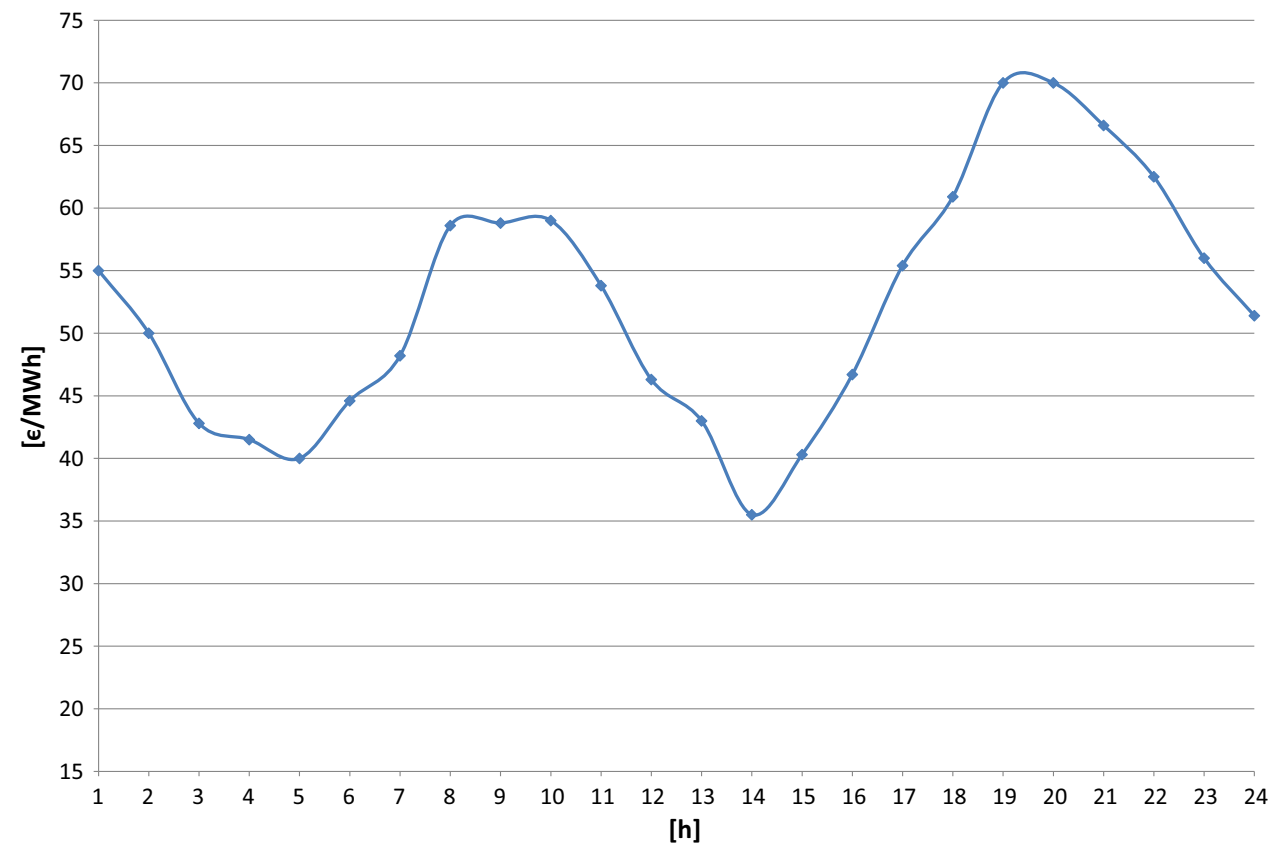

Table 6 Pre-shift state with RTP2 rate

\begin{tabular}{lcccccccc}
\hline Hour & $\rho_{t}$ & $P_{G_{t, 1}}$ & $P_{G_{t, 2}}$ & $P_{G_{t, 3}}$ & $P_{G_{t, 4}}$ & $\sum_{j \in \Omega_{G}} P_{G_{t, j}}$ & $P_{g r i d_{t}}$ & $\sum_{j \in \Omega_{D_{e}}} P_{D_{e_{t, j}}}$ \\
\hline 1 & 55.0 & 400.0 & 180.0 & 20.7 & 17.0 & 617.7 & -205.4 & 412.3 \\
2 & 50.0 & 400.0 & 180.0 & 10.0 & 10.0 & 600.0 & -235.3 & 364.7 \\
3 & 42.8 & 400.0 & 180.0 & 10.0 & 10.0 & 600.0 & -251.2 & 348.8 \\
4 & 41.5 & 400.0 & 180.0 & 10.0 & 10.0 & 600.0 & -330.4 & 269.6 \\
5 & 40.0 & 400.0 & 180.0 & 10.0 & 10.0 & 600.0 & -330.4 & 269.6 \\
6 & 44.6 & 400.0 & 180.0 & 10.0 & 10.0 & 600.0 & -187.7 & 412.3 \\
7 & 48.2 & 400.0 & 180.0 & 10.0 & 10.0 & 600.0 & -61.0 & 539.0 \\
8 & 58.6 & 400.0 & 180.0 & 28.8 & 35.0 & 643.8 & 85.6 & 729.4 \\
9 & 58.8 & 400.0 & 180.0 & 29.2 & 36.0 & 645.2 & 68.3 & 713.5 \\
10 & 59.0 & 400.0 & 180.0 & 29.7 & 37.0 & 646.7 & 66.8 & 713.5 \\
11 & 53.8 & 400.0 & 180.0 & 18.0 & 11.0 & 609.0 & 199.7 & 808.7 \\
12 & 46.3 & 400.0 & 180.0 & 10.0 & 10.0 & 600.0 & 224.5 & 824.5 \\
13 & 43.0 & 400.0 & 180.0 & 10.0 & 10.0 & 600.0 & 161.1 & 761.1 \\
14 & 35.5 & 400.0 & 180.0 & 10.0 & 10.0 & 600.0 & 145.2 & 745.2 \\
15 & 40.3 & 400.0 & 180.0 & 10.0 & 10.0 & 600.0 & 81.8 & 681.8 \\
16 & 46.7 & 400.0 & 180.0 & 10.0 & 10.0 & 600.0 & 66.0 & 666.0 \\
17 & 55.4 & 400.0 & 180.0 & 21.6 & 19.0 & 620.6 & 330.8 & 951.4 \\
18 & 60.9 & 400.0 & 180.0 & 34.0 & 46.5 & 660.5 & 560.4 & 1220.9 \\
19 & 70.0 & 400.0 & 180.0 & 54.4 & 60.0 & 694.4 & 637.5 & 1331.9 \\
20 & 70.0 & 400.0 & 180.0 & 54.4 & 60.0 & 694.4 & 669.2 & 1363.6 \\
21 & 66.6 & 400.0 & 180.0 & 46.8 & 60.0 & 686.8 & 565.8 & 1252.6 \\
22 & 62.5 & 400.0 & 180.0 & 37.6 & 54.5 & 672.1 & 374.4 & 1046.5 \\
23 & 56.0 & 400.0 & 180.0 & 22.9 & 22.0 & 624.9 & 136.2 & 761.1 \\
\hline 4 & 51.4 & 400.0 & 180.0 & 12.6 & 10.0 & 602.6 & -127.1 & 475.5 \\
\hline & & & & & & & &
\end{tabular}




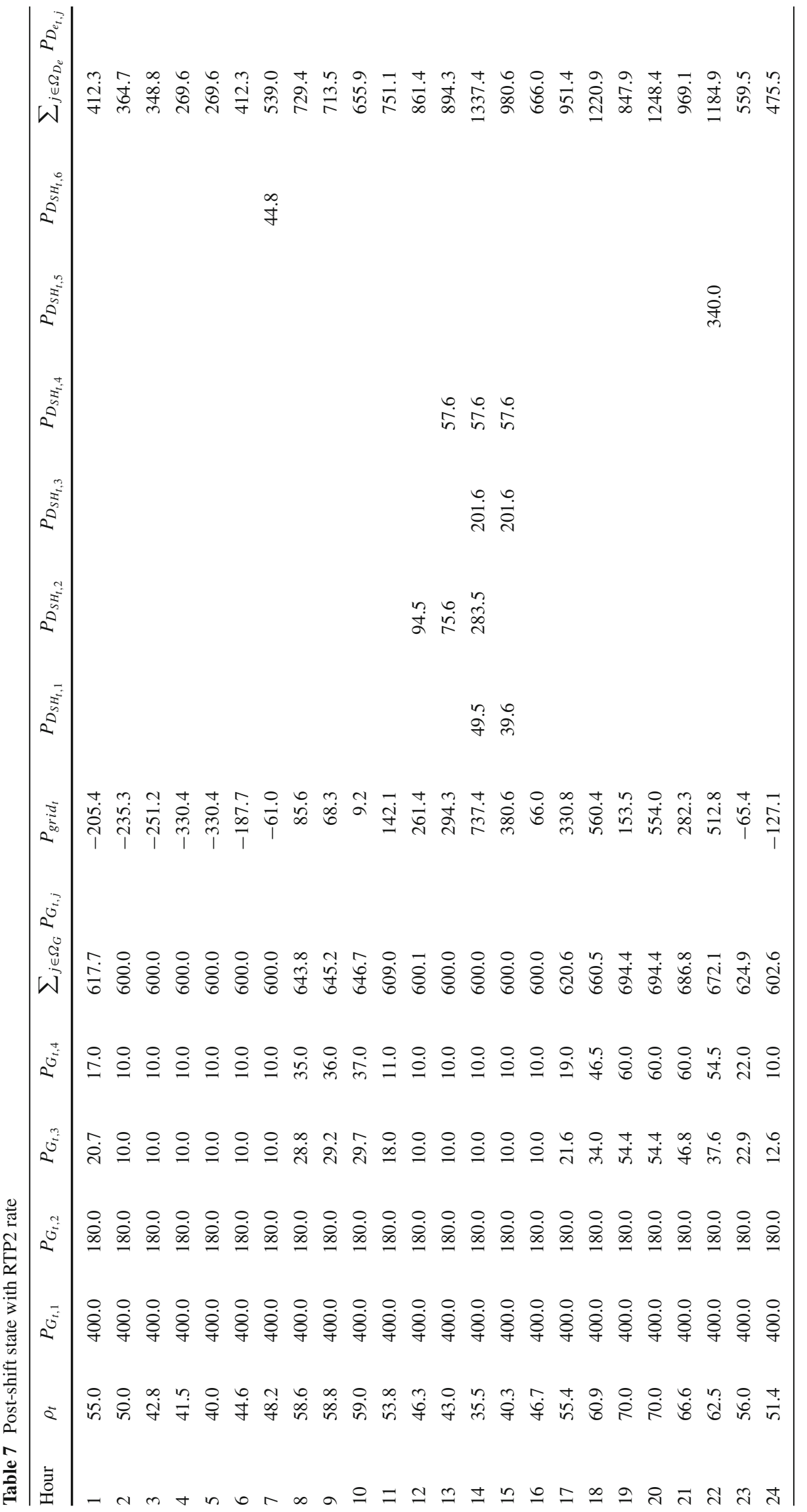


Fig. 8 Pre-shift state: utility and microgrid load with RTP2 rate

Fig. 9 Post-shift state: utility and microgrid load with RTP2 rate
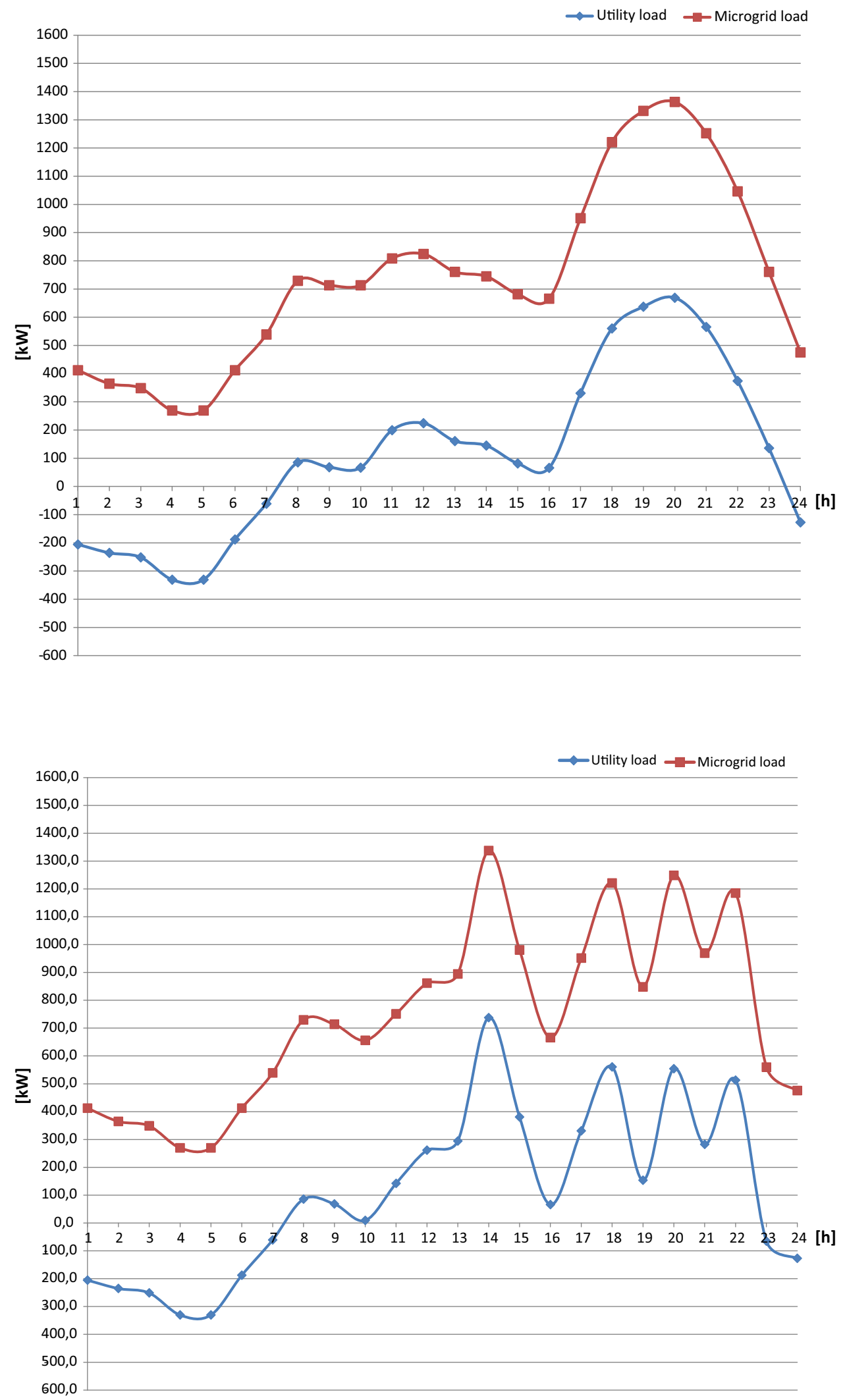


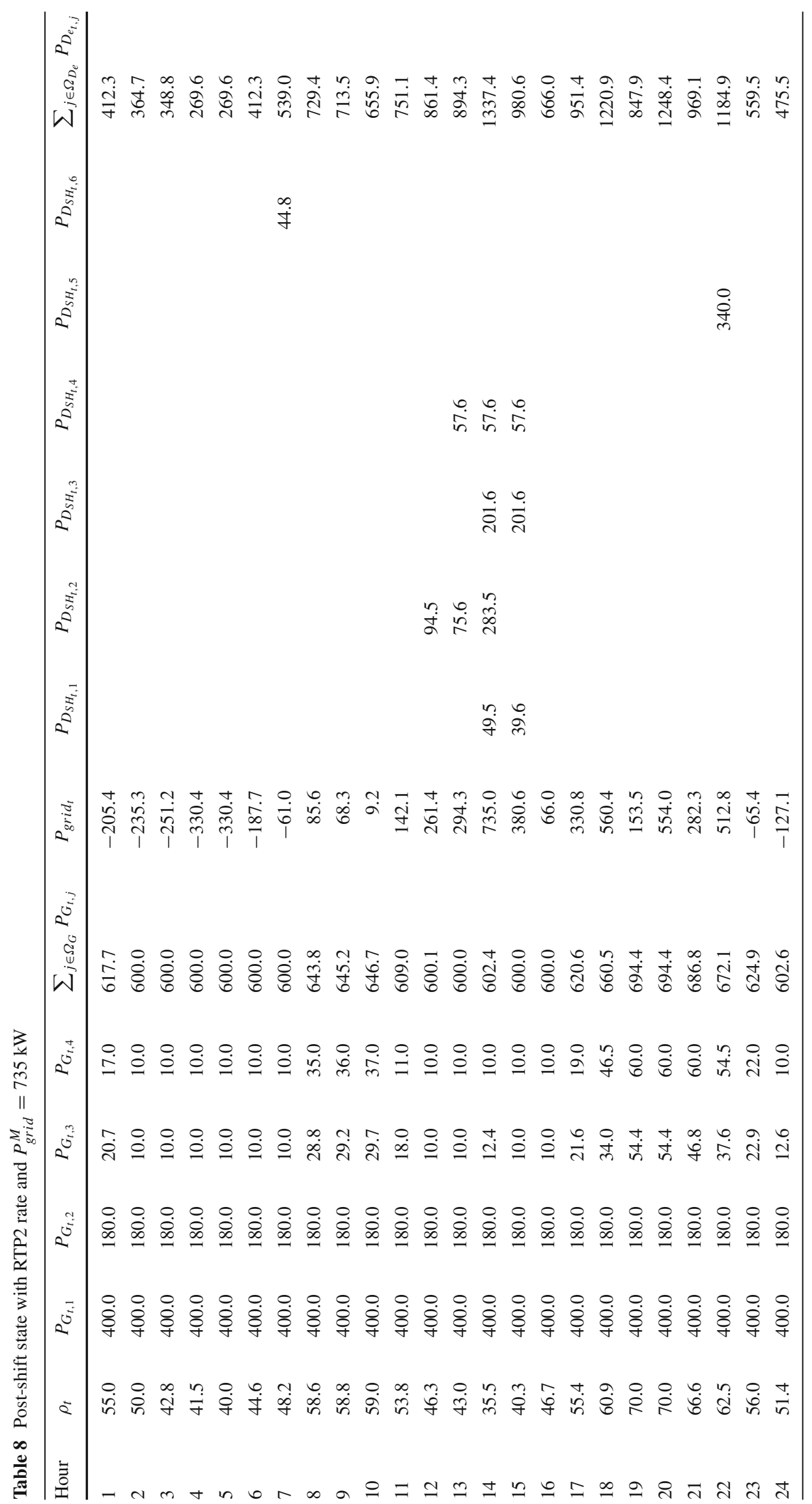




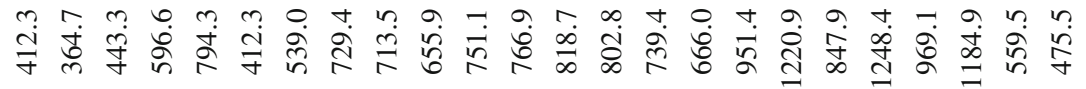

i
in in

ह

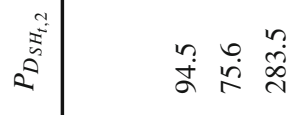

है

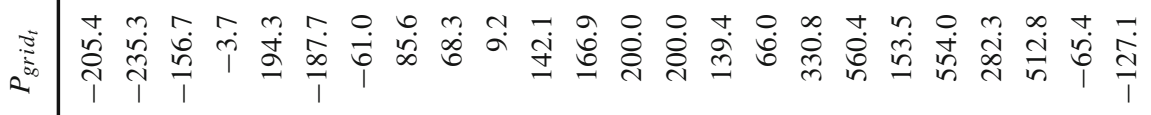

$2^{5}$

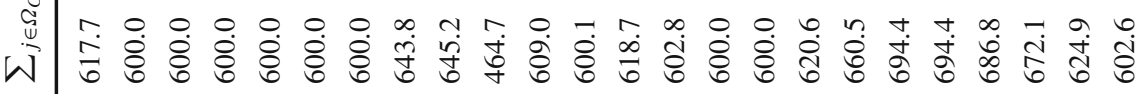

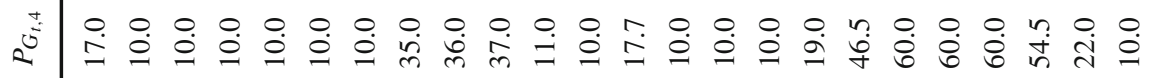

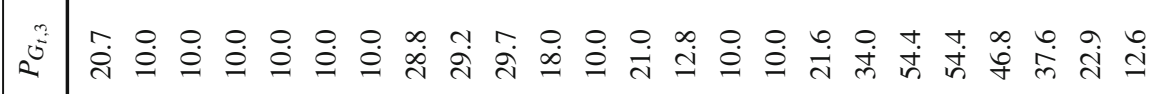

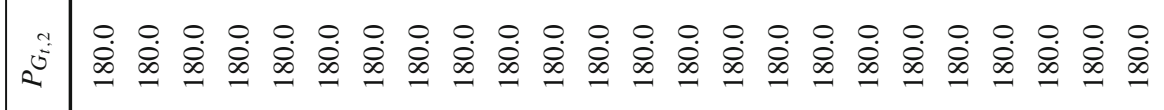

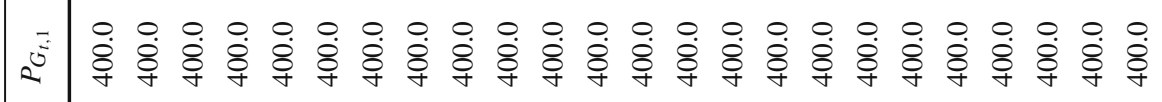

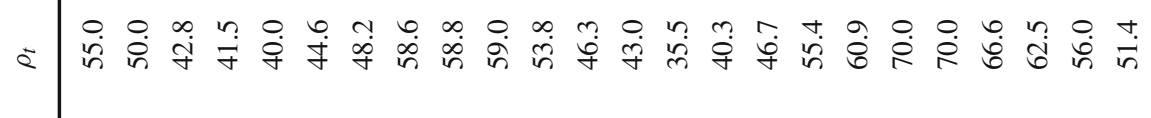
言 
Table 10 Pre-shift state in presence of storage and with RTP2 rates

\begin{tabular}{|c|c|c|c|c|c|c|c|c|c|c|c|}
\hline Hour & $\rho_{t}$ & $\sum_{j \in \Omega_{D_{e}}} P_{D_{S H_{t}}}$ & $P_{G_{t, 1}}$ & $P_{G_{t, 2}}$ & $P_{G_{t, 3}}$ & $P_{G_{t, 4}}$ & $\sum_{j \in \Omega_{G}} P_{G_{t, j}}$ & $P_{\text {grid }_{t}}$ & $P_{S E_{t}}$ & $E_{S E_{t}}$ & $\sum_{j \in \Omega_{D_{e}}} P_{D_{e_{t, j}}}^{\prime}$ \\
\hline 1 & 55.0 & 412.3 & 400.0 & 180.0 & 20.7 & 17.0 & 617.7 & -505.4 & -300.0 & -1500.0 & 112.3 \\
\hline 2 & 50.0 & 364.7 & 400.0 & 180.0 & 10.0 & 10.0 & 600.0 & 64.7 & 300.0 & -1200.0 & 664.7 \\
\hline 3 & 42.8 & 348.8 & 400.0 & 180.0 & 10.0 & 10.0 & 600.0 & 48.8 & 300.0 & -900.0 & 648.8 \\
\hline 4 & 41.5 & 269.6 & 400.0 & 180.0 & 10.0 & 10.0 & 600.0 & -30.4 & 300.0 & -600.0 & 569.6 \\
\hline 5 & 40.0 & 269.6 & 400.0 & 180.0 & 10.0 & 10.0 & 600.0 & -30.4 & 300.0 & -300.0 & 569.6 \\
\hline 6 & 44.6 & 412.3 & 400.0 & 180.0 & 10.0 & 10.0 & 600.0 & 112.3 & 300.0 & 0 & 712.3 \\
\hline 7 & 48.2 & 539.0 & 400.0 & 180.0 & 10.0 & 10.0 & 600.0 & 239.0 & 300.0 & 300.0 & 839.0 \\
\hline 8 & 58.6 & 729.4 & 400.0 & 180.0 & 28.8 & 35.0 & 643.8 & -214.4 & -300.0 & 0 & 429.4 \\
\hline 9 & 58.8 & 713.5 & 400.0 & 180.0 & 29.2 & 36.0 & 645.2 & -231.7 & -300.0 & -300.0 & 413.5 \\
\hline 10 & 59.0 & 713.5 & 400.0 & 180.0 & 29.7 & 37.0 & 646.7 & -233.2 & -300.0 & -600.0 & 413.5 \\
\hline 11 & 53.8 & 808.7 & 400.0 & 180.0 & 18.0 & 11.0 & 609.0 & -100.3 & -300.0 & -900.0 & 508.7 \\
\hline 12 & 46.3 & 824.5 & 400.0 & 180.0 & 10.0 & 10.0 & 600.0 & 524.5 & 300.0 & -600.0 & 1124.5 \\
\hline 13 & 43.0 & 761.1 & 400.0 & 180.0 & 10.0 & 10.0 & 600.0 & 461.1 & 300.0 & -300.0 & 1061.1 \\
\hline 14 & 35.5 & 745.2 & 400.0 & 180.0 & 10.0 & 10.0 & 600.0 & 445.2 & 300.0 & 0 & 1045.2 \\
\hline 15 & 40.3 & 681.8 & 400.0 & 180.0 & 10.0 & 10.0 & 600.0 & 381.8 & 300.0 & 300.0 & 981.8 \\
\hline 16 & 46.7 & 666.0 & 400.0 & 180.0 & 10.0 & 10.0 & 600.0 & 366.0 & 300.0 & 600.0 & 966.0 \\
\hline 17 & 55.4 & 951.4 & 400.0 & 180.0 & 21.6 & 19.0 & 620.6 & 30.8 & -300.0 & 300.0 & 651.4 \\
\hline 18 & 60.9 & 1220.9 & 400.0 & 180.0 & 34.0 & 46.5 & 660.5 & 260.4 & -300.0 & 0 & 920.9 \\
\hline 19 & 70.0 & 1331.9 & 400.0 & 180.0 & 54.4 & 60.0 & 694.4 & 337.5 & -300.0 & 0 & 1031.9 \\
\hline 20 & 70.0 & 1363.6 & 400.0 & 180.0 & 54.4 & 60.0 & 694.4 & 369.2 & -300.0 & -300.0 & 1063.6 \\
\hline 21 & 66.6 & 1252.6 & 400.0 & 180.0 & 46.8 & 60.0 & 686.8 & 265.8 & -300.0 & -600.0 & 952.6 \\
\hline 22 & 62.5 & 1046.5 & 400.0 & 180.0 & 37.6 & 54.5 & 672.1 & 74.0 & -300.0 & -900.0 & 746.5 \\
\hline 23 & 56.0 & 761.1 & 400.0 & 180.0 & 22.9 & 22.0 & 624.9 & -163.8 & -300.0 & -1200.0 & 461.1 \\
\hline 24 & 51.4 & 475.5 & 400.0 & 180.0 & 12.6 & 10.0 & 602.6 & -127.1 & 0 & -1200.0 & 475.5 \\
\hline
\end{tabular}

To avoid the creation of new peaks limits to the power exchanged with the main grid are gradually imposed in intervals $12-16$. Tables 8 and 9 show results of the model in the post-shift state, where $P_{g r i d_{t}}$ is limited at 737 and $200 \mathrm{~kW}$, respectively.

In the first case, $P_{\text {grid }}$ reaches the above mentioned limit in only one interval (at 13-14). The allocation of shiftable loads does not change, but the internal production increases to respect the balance equation, thus changing the difference between the total power absorbed and the total power produced. In the second case, $P_{\text {grid }}$ does not reach the limit. The allocation of the shiftable loads changes, and consequently, whereas the difference between the total power produced and absorbed does not change. The loads shift as in the case with unconstrained RTP1 rate. This means that it is possible limit to the solution also acting on the tariff. As the limit becomes more restrictive, the economic benefits decrease and the flattening indices improve (Tables 12 and 13).

Finally, one only centralized electric storage unit, with a power rating of $300 \mathrm{~kW}$ and a maximum stored energy of $2700 \mathrm{kWh}$, is assumed available. Tables 10 and 11 show the power produced and the energy changed with the main grid in the pre and post-shift states, respectively.
As the summary tables (Tables 12 and 13) show, the presence of the storage, together with DSM, involves the best solution from the economic point of view and the worst solution in terms of flattening of the utility load profile. ${ }^{8}$ It also points out that in the proposed case study, the storage is more effective than the DSM from all point of views, because the management of the storage has less constraints than the DSM.

Figures 10 and 11 show the utility and microgrid load profiles in the post-shift state, with $P_{\text {grid }}^{M}$ equal to 735 e $200 \mathrm{~kW}$, respectively.

Furthermore, adopting the solution (d), as compared with the case (b), there is a slight worsening of the objective function (less than $3 €$ per day), but a marked improvement in flattening conditions. So the solution (d) is the best result, because it brings benefits both to the DSO and the prosumer.

\footnotetext{
${ }^{8}$ Case 1: pre-shift (a) and post-shift (b) state with RTP1 rate. Case 2: pre-shift state with RTP2 rate (a), post-shift state with RTP2 rate (b), post-shift state with RTP2 rate and $P_{\text {grid }}^{M}=735 \mathrm{~kW}(\mathrm{c})$, post-shift state with RTP2 rate and $P_{\text {grid }}^{M}=200 \mathrm{~kW}(\mathrm{~d})$, pre-shift state in presence of storage system with RTP2 rate (e), post-shift state in presence of storage system with RTP2 rate (f).
} 


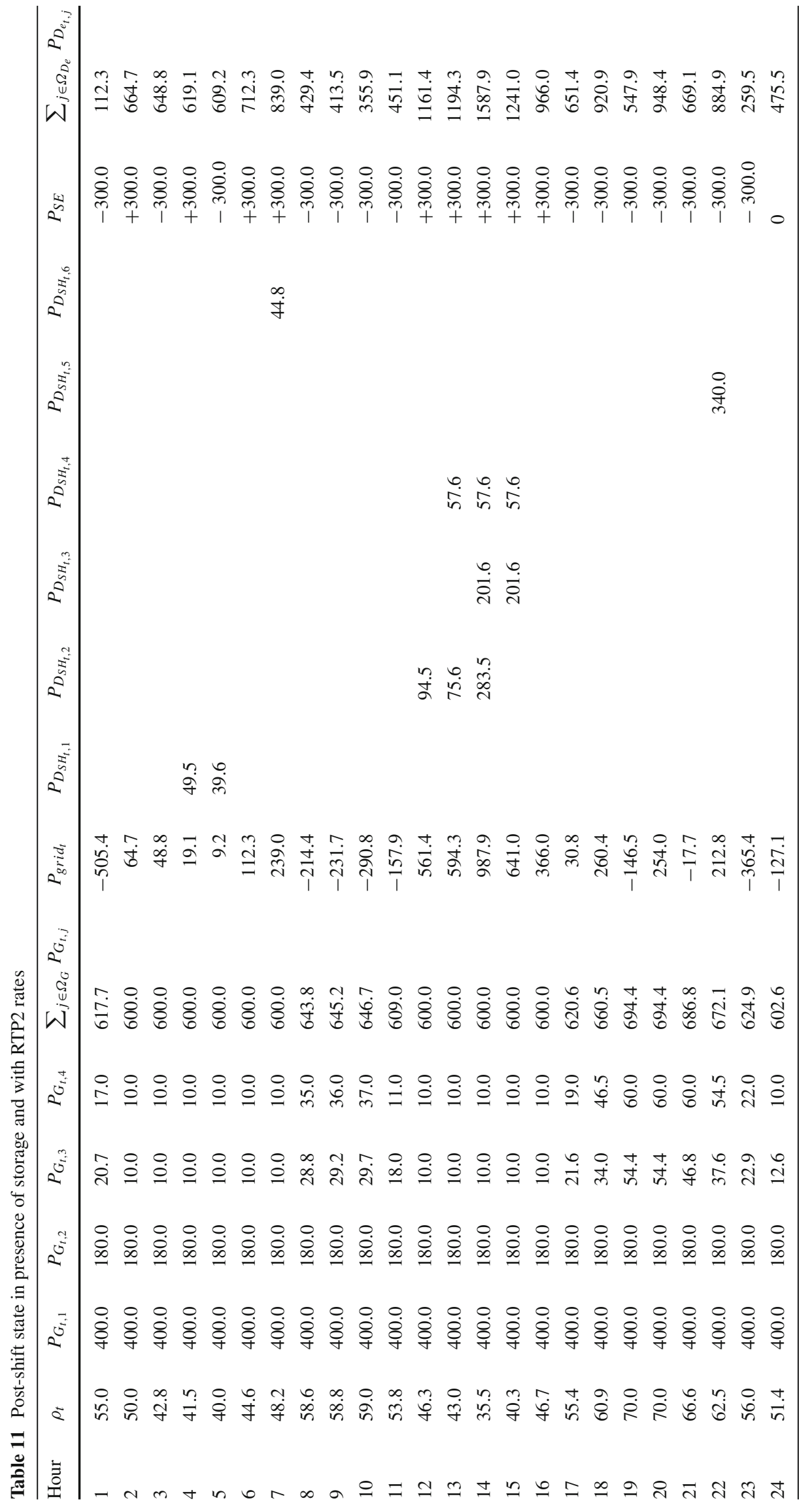


Table 12 Economical objective function: values and percentages of reduction

Table 13 Indices of flattening of utility load profile

Fig. 10 Post-shift state: utility and microgrid load with RTP2 rate and $P_{\text {grid }}^{M}=735 \mathrm{~kW}$

\begin{tabular}{|c|c|c|c|c|c|c|c|c|}
\hline \multirow[t]{2}{*}{ Index } & \multicolumn{2}{|l|}{ Case 1} & \multicolumn{6}{|l|}{ Case 2} \\
\hline & $a$ & $b$ & $a$ & $b$ & $c$ & $d$ & $e$ & $f$ \\
\hline Value $[€]$ & 696.6 & 672.8 & 685.1 & 655.6 & 655.7 & 658.1 & 610.8 & 581.6 \\
\hline Value reduction & & -3.4 & & -4.3 & -4.3 & -3.9 & -6.8 & -11.3 \\
\hline
\end{tabular}

\begin{tabular}{|c|c|c|c|c|c|c|c|c|}
\hline \multirow[t]{2}{*}{ Index } & \multicolumn{2}{|c|}{ Case 1} & \multicolumn{6}{|c|}{ Case 2} \\
\hline & $a$ & $b$ & $a$ & $b$ & $c$ & $d$ & $e$ & $f$ \\
\hline Peak [kW] & 669.2 & 560.4 & 669.2 & 737.4 & 735.0 & 560.4 & 524.5 & 987.9 \\
\hline Peak variation & & -16.3 & & +10.2 & +9.8 & -16.3 & -21.6 & +47.6 \\
\hline Peak to valley $[\mathrm{kW}]$ & 996.6 & 795.7 & 999.6 & 1067.8 & 1065.4 & 795.7 & 1029.9 & 1493.3 \\
\hline Load factor & 14.4 & 17.2 & 16.5 & 14.9 & 15.0 & 19.5 & 18.6 & 9.9 \\
\hline SQRT & 301.0 & 299.4 & 299.8 & 303.9 & 303.6 & 227.8 & 270.0 & 353.0 \\
\hline
\end{tabular}

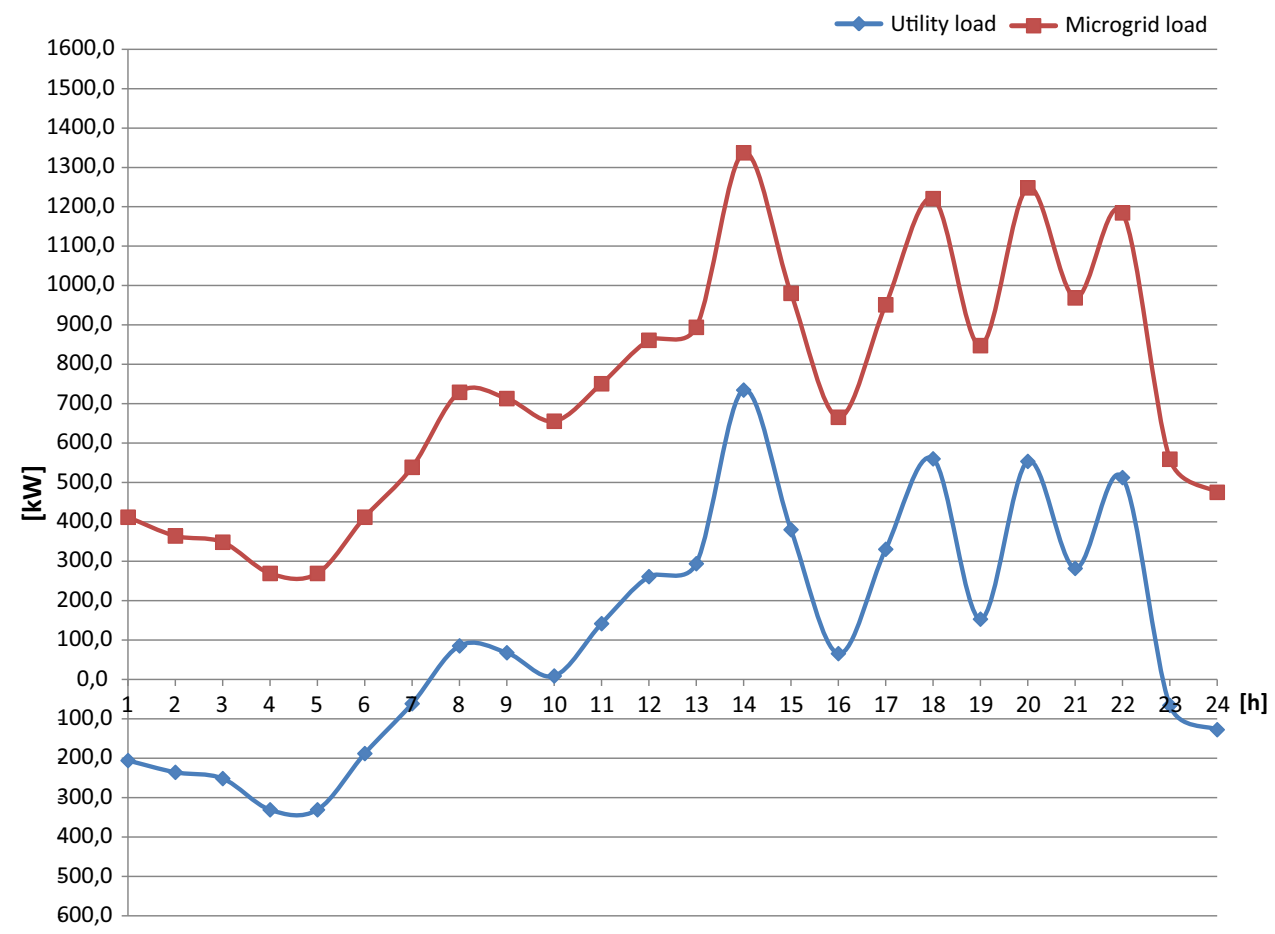

Figures 12 and 13 show the utility and microgrid load profiles in pre and post-shift states, respectively.

\section{Conclusions}

In this paper, DSM characterized only by shifting techniques is applied to a residential microgrid, managed by a prosumer. The DSM is considered as an integral part of the optimal economic short-term management problem, so that the allocation of shiftable loads is treated as a variable, like the energy exchanged with the main grid, the internal production and the charge/discharge of electrical storage units. The main purpose of the work is to show by solving the optimization problem how, the variable allocation of shiftabe loads is related to the other variables involved, and how all the variables are related, directly or indirectly, to the energy price and to other parameters typical of shiftable devices. To deal with these goals, an efficient optimization model is formulated and implemented including the functional links between the shiftable and shifted loads. The optimal values of all the variables are simultaneously determined. The model is applied to a microgrid involving four thermoelectric power plants and a photovoltaic plant. Washing machines, washing machines with dryers, dishwashers, electric air conditioners, irons and coffee makers are considered shiftable loads. The 
Fig. 11 Post-shift state: utility and microgrid load with RTP2 rate and $P_{\text {grid }}^{M}=200 \mathrm{~kW}$

Fig. 12 Pre-shift state: utility and microgrid load in presence of storage, with RTP2 rate
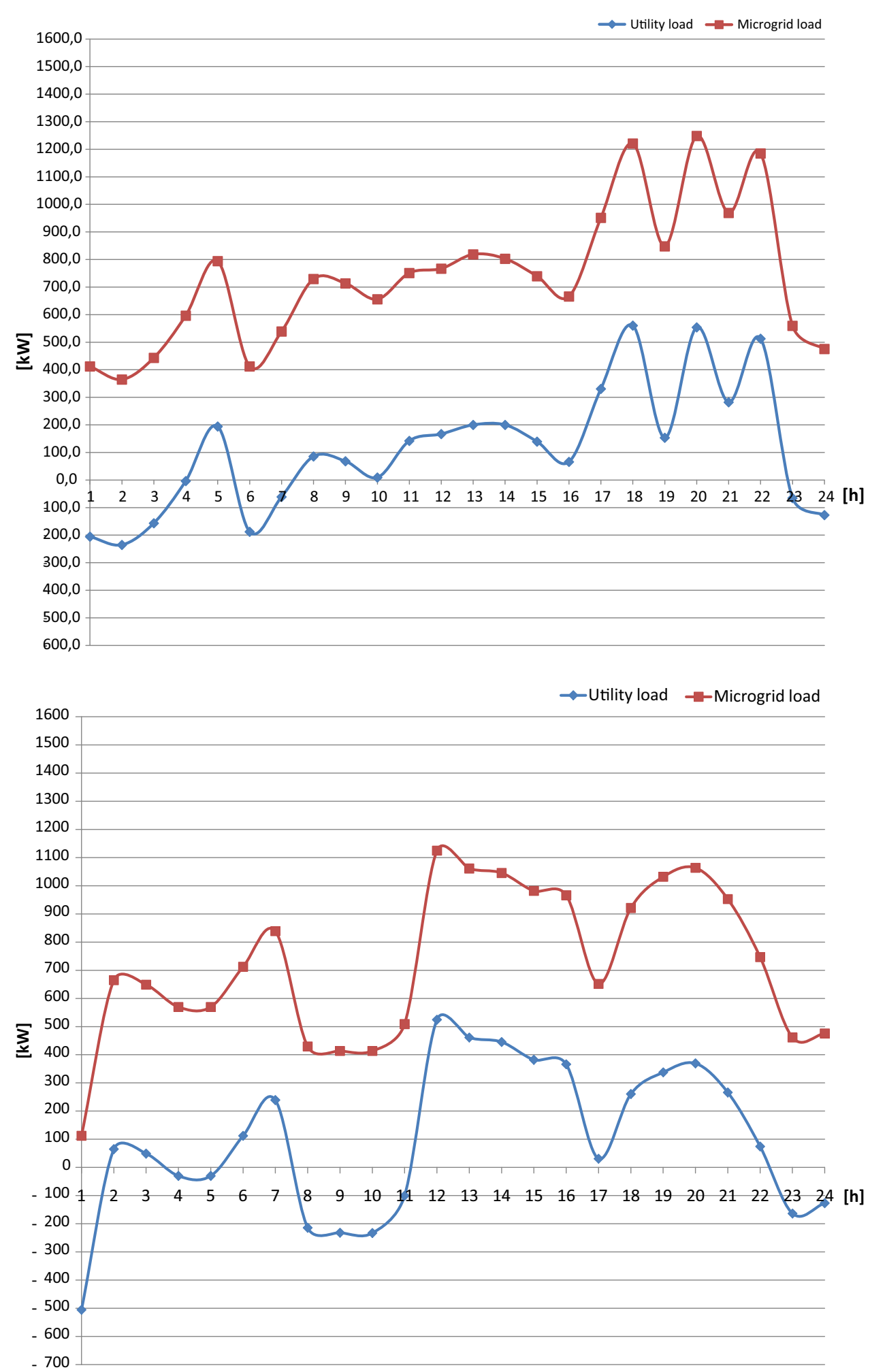

total number of such devices is 1260 . Based on the shifting criteria established for the two tariff regimes (RTP and TOU) results show how the effectiveness of the shift (i.e. the ability to improve the objective of the prosumer) increases with: the difference between the maximum and minimum price; the percentage of load shifted from high energy price hours to low energy price hours; the flexibility to use devices and the amplitude of the time windows. The case of DSM producing new peak loads is also considered. Results show that the achievement of an important economic benefit corresponds 
Fig. 13 Post-shift state: utility and microgrid load in presence of storage, with RTP2 rate

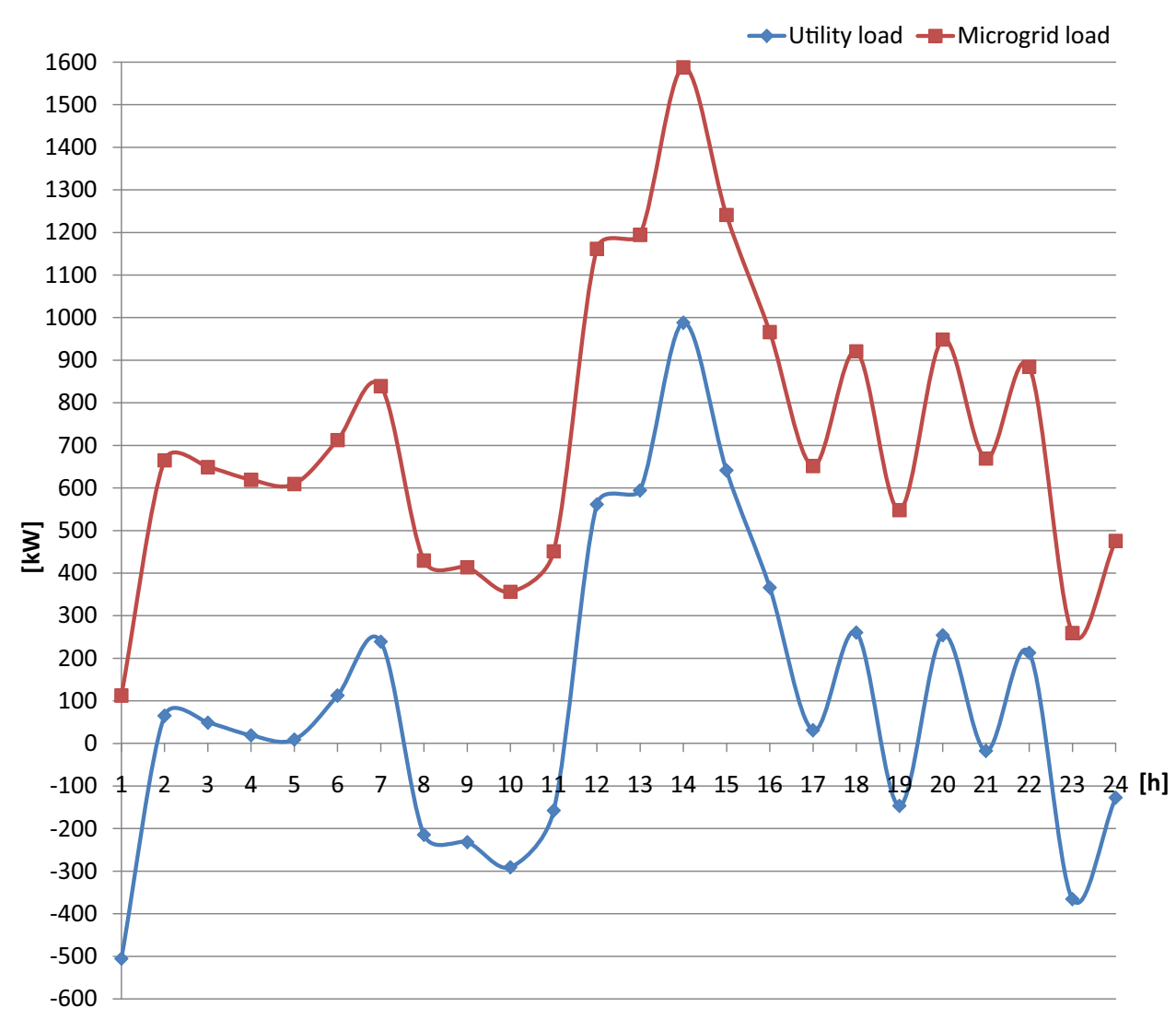

to a worsening of the indices of flattening of utilityload diagram. A sensitivity analysis is also performed by varying the maximum limit, imposed by DSO, on the power exchanged with the main grid, in order to find the value of the power limit that shaves the peaks of the utility load diagram, induced by DSM. The resultant low economic losses for the prosumer highlight that, for the application considered, it is not necessary to find a compromise solution. On the other hand, results point out that DSM provides a great opportunity for the net balance of the local load in short-term management, or, rather, as storage, to compensate the intermittency of non programmable renewable sources. Future work will focus on the study of this application for a smart grid.

\section{References}

1. Behrangrad, M.: A review of demand side management business models in the electricity market. Renew. Sustain. Energy Rev. 47, 270-283 (2015)

2. Siano, P.: Demand response and smart grids-a survey. Renew. Sustain. Energy Rev. 30, 461-478 (2014)

3. CESI. Centro Elettrotecnico Sperimentale Italiano Dipartimento di Ingegneria elettrica dell'Università degli Studi di Bologna "Definizione del modello di carico elettrico e termico di tipiche utenze civili e industriali per la progettazione del sistema di con- trollo di un impianto integrato celle a combustibile - microturbina a gas per la generazione distribuita”, REPORT (2000)

4. Kinhekar, N., Padhy, N., Gupta, H.: Multiobjective demand side management solutions for utilities with peak demand deficit. Int. J. Electr. Power Energy Syst. 55, 612-619 (2014)

5. Schwaegerl, C., et al.: Technical, social, economic, and environmental benefits provided by microgrids on power system operation. Advanced architectures and control concepts for more microgrids, Final report (2009)

6. Wang, J., Kennedy, S., Kirtley, J.: A new wholesale bidding mechanism for enhanced demand response in smart grids. In: Innovative smart grid technologies (ISGT). pp 1-8 (2010)

7. Paulus, M., Borggrefe, F.: The potential of demand-side management in energy-intensive industries for electricity markets in Germany. Appl. Energy 88, 432-441 (2011)

8. Mohsenian-Rad, A.H., Wong, V., Jatskevich, J., Schober, R., Leon-Garcia, A.: Autonomous demand-side management based on game-theoretic energy consumption scheduling for the future smart grid. IEEE Trans. Smart Grid 1(3), 320-331 (2010b)

9. Boivin, J.: Demand side management the role of the power utility. Pattern Recognit. 28(10), 1493-1497 (1995)

10. Silva, Pina A.C., Ferrao, P.: The impact of demand side management strategies in the penetration of renewable electricity. Energy 41(1), 128-137 (2012)

11. Xu, W., Zhou, M., Wang, H., Liu, H.: A load management optimization approach considering economic efficiency and load profile. In: China International Conference on Electricity Distribution (CICED). pp. 907-911 (2014)

12. Marnay, C., Asano, H., Papathanassiou, S., Strbac, G.: Policy making for microgrids: economic and regulatory issues of microgrid implementation. IEEE Power Energy Mag. 6, 11-18 (2008) 
13. Strbac, G.: Demand side management: benefits and challenges. Energy Policy 36(12), 4419-4426 (2008)

14. Albadi, M.H., El-Saadany, E.: A summary of demand response in electricity markets. Electr. Power Syst. Res. 78(11), 1989-1996 (2008)

15. Fernandes, F., Morais, H., Vale, Z., Ramos, C.: Dynamic load management in a smart home to participate in demand response events. Energy Build. 82, 592-606 (2014)

16. Mohsenian-Rad, A., Leon-Garcia, A.: Optimal residential load control with price prediction in real-time electricity pricing environments. IEEE Trans. Smart Grid 1(2), 120-133 (2010)

17. Gottwalt, S., Ketter, W., Block, C., Collins, J., Weinhardt, C.: Demand side managementa simulation of household behavior under variable prices. Energy Policy 39(12), 8163-8174 (2011)

18. Graditi, G., Di Silvestre, M., Gallea, R., Riva Sanseverino, E.: Heuristic-based shiftable loads optimal management in smart micro-grids. IEEE Trans. Ind. Inform. 11(1), 271-280 (2015)

19. Khodaei, M.A., Shahidehpour, Choi, J.: Optimal hourly scheduling of community-aggregated electricity consumption. J. Electr. Eng. Technol. 8, 1251-1260 (2013)

20. Logenthiran, T., Srinivasan, D., Shun, T.: Demand side management in smart grid using heuristic optimization. IEEE Trans. Smart Grid 3, 1244-1252 (2012)

21. Malik, O., Havel, P.: Active demand-side management system to facilitate integration of res in low-voltage distribution networks. IEEE Trans. Sustain. Energy 5(2), 673-681 (2014)

22. Mohsenian-Rad, A.H., Wong, V., Jatskevich, J., Schober, R.: Optimal and autonomous incentive-based energy consumption scheduling algorithm for smart grid. In: Innovative Smart Grid Technologies (ISGT), pp 1-6 (2010)

23. Di Silvestre, M., Graditi, G., Sanseverino, E.: A generalized framework for optimal sizing of distributed energy resources in micro-grids using an indicator-based swarm approach. IEEE Trans. Ind. Inform. 10(1), 152-162 (2014)

24. Graditi, G., Sanseverino, E., Di Silvestre, M., Gallea, R., Zizzo, G.: Managing electrical energy storage systems and shiftable loads with an innovative approach in energy districts. In: International Symposium on Power Electronics, Electrical Drives, Automation and Motion (SPEEDAM). pp. 1085-1091 (2014)
25. Grijalva, S., Costley, M., Ainsworth, N.: Prosumer-based control architecture for the future electricity grid. In: IEEE International Conference on Control Applications (CCA). pp. 43-48 (2011)

26. Nguyen, D., Le, L.: Optimal bidding strategy for microgrids considering renewable energy and building thermal dynamics. IEEE Trans. Smart Grid 5(4), 1608-1620 (2014)

27. Shandurkova, I., Bremdal, A., Bacher, R., Ottesen, S., Nilsen, A.: A prosumer oriented energy market—a state of the art perspective. IMPROSUME Publication Series (2012)

28. Vogt, H., Weiss, H., Spiess, P., Karduck, A.: Market based prosumer participation in the smart grid. 4th IEEE International Conference on Digital Ecosystems and Technologies (DEST). pp. 592-597 (2010)

29. Mazidi, M., Zakariazadeh, A., Jadid, S., Siano, P.: Integrated scheduling of renewable generation and demand response programs in a microgrid. Energy Convers. Manag. 86, 1118-1127 (2014)

30. Zakariazadeh, A., Jadid, S., Siano, P.: Smart microgrid energy and reserve scheduling with demand response using stochastic optimization. Int. J. Electr. Power Energy Syst. 63, 523-533 (2014)

31. Barbato, A., Capone, A., Carello, G., Delfanti, M., Merlo, M., Zaminga, A.: House energy demand optimization in single and multi-user scenarios. pp. 345-350 (2011)

32. Rossi, F., Russo, A.: Optimal management of an industrial power plant in a deregulated market. In: 39th International Universities Power Engineering Conference, UPEC 2004, vol. 3, pp. 1073-1077 (2004)

33. Aalami, H., Moghaddam, M., Yousefi, G.: Modeling and prioritizing demand response programs in power markets. Electr. Power Syst. Res. 80(4), 426-435 (2010) 